Article

\title{
Geographic Graph Network for Robust Inversion of Particulate Matters
}

\author{
Lianfa $\mathrm{Li}^{1,2}$
}

check for

updates

Citation: Li, L. Geographic Graph Network for Robust Inversion of Particulate Matters. Remote Sens. 2021,

13, 4341. https://doi.org/

$10.3390 /$ rs13214341

Academic Editor: Dimitrios Balis

Received: 13 September 2021

Accepted: 26 October 2021

Published: 28 October 2021

Publisher's Note: MDPI stays neutral with regard to jurisdictional claims in published maps and institutional affiliations.

Copyright: (C) 2021 by the author. Licensee MDPI, Basel, Switzerland. This article is an open access article distributed under the terms and conditions of the Creative Commons Attribution (CC BY) license (https:// creativecommons.org/licenses/by/ $4.0 /)$.
1 State Key Laboratory of Resources and Environmental Information Systems, Institute of Geographic Sciences and Natural Resources Research, Chinese Academy of Sciences, Datun Road, Beijing 100101, China; lilf@igsnrr.ac.cn; Tel.: +86-010-6488-8362

2 College of Resources and Environment, University of the Chinese Academy of Sciences, Beijing 100049, China

Abstract: Although remote sensors have been increasingly providing dense data and deriving reanalysis data for inversion of particulate matters, the use of these data is considerably limited by the ground monitoring samples and conventional machine learning models. As regional criteria air pollutants, particulate matters present a strong spatial correlation of long range. Conventional machine learning cannot or can only model such spatial pattern in a limited way. Here, we propose a method of a geographic graph hybrid network to encode a spatial neighborhood feature to make robust estimation of coarse and fine particulate matters $\left(\mathrm{PM}_{10}\right.$ and $\left.\mathrm{PM}_{2.5}\right)$. Based on Tobler's First Law of Geography and graph convolutions, we constructed the architecture of a geographic graph hybrid network, in which full residual deep layers were connected with graph convolutions to reduce over-smoothing, subject to the $\mathrm{PM}_{10}-\mathrm{PM}_{2.5}$ relationship constraint. In the site-based independent test in mainland China (2015-2018), our method achieved much better generalization than typical state-of-the-art methods (improvement in $\mathrm{R}^{2}$ : 8-78\%, decrease in RMSE: $14-48 \%$ ). This study shows that the proposed method can encode the neighborhood information and can make an important contribution to improvement in generalization and extrapolation of geo-features with strong spatial correlation, such as $\mathrm{PM}_{2.5}$ and $\mathrm{PM}_{10}$.

Keywords: geographic graph hybrid network; graph convolution; neighborhood feature; $\mathrm{PM}_{2.5}$; $\mathrm{PM}_{10}$; spatiotemporal modeling; loss constraint

\section{Introduction}

As criteria air pollutants, particulate matters have adverse health effects [1] and important influence on climate changes [2-4]. For fine particulate matter (PM) with a diameter of 2.5 microns or less $\left(\mathrm{PM}_{2.5}\right)$, short-term exposure has been shown to be associated with respiratory symptoms, acute and chronic bronchitis, asthma attacks, and restricted activity days, etc. $[5,6]$. For particulate matter with a diameter of 10 microns or less $\left(\mathrm{PM}_{10}\right)$, short-term exposure has been reported to be associated with worsening asthma and chronic obstructive pulmonary disease etc. [7-9]. Long-term (months to years) exposure to $\mathrm{PM}_{2.5}$ and $\mathrm{PM}_{10}$ has been linked to premature death, reduced lung function and lung cancer, etc. $[9,10]$. On the other hand, as a particulate component of PM, black carbon-mainly from combustion - considerably contributes to climate warming, but as another component of PM, particulate sulfates cool the atmosphere of the Earth [11]. Accurate estimation of $\mathrm{PM}_{2.5}$ and $\mathrm{PM}_{10}$ is important for their emission track, prevention and control and health effect evaluation [12,13].

As ground aerosols, PMs are closely associated with aerosol optimal depth (AOD) that can be used as a critical input parameter for concentration estimation. There are a wide range of AOD remote sensing products, from the early Advanced Very High Resolution Radiometer (AVHRR), the Global Ozone Monitoring Experiment (GOME), the Moderate Resolution Imagining Spectroradiometer (MODIS), to the recent Visible Infrared Imaging Radiometer Suite (VIIRS) and Advanced Himawari Imager (AHI). Compared with the 
other AOD products, MODIS has a wide field of view with daily global observations of the Earth and is used as a mainstream AOD sensor [14,15]. As a recent advanced algorithm for retrieving MODIS AOD, Multi-Angle Implementation of Atmospheric Correction (MAIAC) [16-19] can provide an AOD product of better quality at a higher spatial resolution $(1 \mathrm{~km})$, compared with the previous algorithms including Dark Target and Deep Blue $[20,21]$. Compared with remote sensing satellites, unmanned aerial vehicles (UAVs) have recently been increasingly used to collect sensed aerosol or vertical data with higher spatial resolution [22-24]. In addition, the second Modern-Era Retrospective analysis for Research and Applications (MERRA-2) Global Modeling Initiative's (GMI) reanalysis data [25] provides important vertical meteorological and emission information for $\mathrm{PM}_{2.5}$ and $\mathrm{PM}_{10}$ estimation. As a simulation for the atmospheric composition community, MERRA-2 GMI is driven by MERRA-2 variables (winds, temperature, and pressure, etc.), coupled to the GMI stratosphere-troposphere chemical mechanism, and can provide valuable component emission data including black carbon, organic carbon, dimethyl sulfide, dust, ozone and sulfur dioxide [26], etc.

In the era of big data, although remote sensors and UAVs can provide massive aerosolrelated data streams covering global time and space, ground monitoring data are still very limited for the inversion of ground aerosol pollutants, including $\mathrm{PM}_{2.5}$ and $\mathrm{PM}_{10}$. Ground monitoring data are essential for PM estimation, because training, validation, and testing data need to be selected from them. For mainland China, which covers an area of about 9.6 million square kilometers, there are only about 1594 PM routine state-controlled monitoring sites; on average, each monitoring site covers about 6000 square kilometers. As regional criteria air pollutants, $\mathrm{PM}_{2.5}$ and $\mathrm{PM}_{10}$ present a long-range highly correlated spatial pattern in comparison with traffic-related nitrogen dioxide $\left(\mathrm{NO}_{2}\right)$ [27-29]. Therefore, aerosol, weather, land use, altitude and other surrounding environmental conditions have important influence on the PM concentration and diffusion at a location. Consequently, modeling the surrounding feature based on remote sensing, meteorology and land-use data are important for inversion of $\mathrm{PM}_{2.5}$ and $\mathrm{PM}_{10}$. The mechanism-based models include dispersion models such as CALINE4 [30], and chemical transport models such as GEOS-Chem [31] and CMAQ [32,33], and take into account the influence of neighborhoods through the physiochemical process of atmospheric pollutants. However, the applications of these models are subject to insufficient emission inventory, coarse-resolution meteorological input and challenging assumptions for their parameterization of the atmospheric process. In practical applications in mainland China, they underestimated [34] or overestimated [35] $\mathrm{PM}_{2.5}$ concentrations at coarse spatial resolution, and subsequently introduced bias for downstream applications including health effect evaluation of PM [36-38].

As a type of spatial regression, geostatistical methods [39] range from simple kriging and ordinary kriging to universal and Bayesian kriging [40] and cokriging [41,42], and involve modeling of surrounding covariates for cokriging and of the dependent variable in neighborhood for the other kriging methods. However, due to the uncertainty in fitting of the variogram used in kriging or cokriging, compared with modern machine learning methods, the generalization of the geostatistics method is limited for the inversion of $\mathrm{PM}_{2.5}$ or $\mathrm{PM}_{10}$ [43-45]. Furthermore, for spatiotemporal estimation of PM, the spatiotemporal variogram in kriging requires the assumption of spatiotemporal isotropy and homogeneity, which is often not satisfied in practice [46]. Compared with kriging, machine learning methods including a generalized additive model (GAM) [47], geographic weighted regression [48,49], mixed-effect models [50,51], XGBoost [52,53], random forest [54], and a full residual deep network [55], etc. have shown higher training performance. However, these methods are based on spatiotemporal points and do not model the neighborhood influence on inversion of $\mathrm{PM}_{2.5}$. As a typical method of deep learning, a convolutional neural network $(\mathrm{CNN})$ can be used to generalize its surrounding features, but discontinuous, irregular, and limited monitoring data prevent $\mathrm{CNN}$ from effectively extracting spatiotemporal patterns from the dense regular data. 
One shortcoming of conventional geostatistical and machine learning methods is the lack or the limited ability in modeling neighborhood information. As a recent deep learning method, the graph neural network (GNN) enables strong interaction modeling from the neighborhood through embedding learning of graph nodes. With a theoretical mathematical basis in spectral graph theory [56], GNN can be used to model complex geometric relationships and their interactions. As a powerful form of geometric deep learning, the GNN can well deal with irregular non-Euclidean data with limited labels, and has achieved many successful applications in a variety of domains including recommendation systems [57,58], physical systems [59], combinational optimization [60], computer vision [61], molecule findings [62] and drug discovery [63,64]. Given irregular monitoring data and complex interactions with environmental factors, GNN is an appropriate tool to encode the neighborhood information for PM pollutants. However, the typical graph network has a fixed network structure and its prediction is just limited to those nodes in the existing network. Such a transductive network cannot be used to make predictions to the unseen or new nodes in the graph, which seriously limits the applications of the graph network in many domains [65]. The existing applications of GNN in predicting PM [66,67] showed such a limitation for generalization and extrapolation.

This paper proposes a novel method of geographical graph hybrid network (GGHN) to generalize the neighborhood feature from the surrounding remote sensed data, and other spatiotemporal covariates to improve spatiotemporal inversion of $\mathrm{PM}_{2.5}$ and $\mathrm{PM}_{10}$. Based on Tobler's First Law of Geography and local graph convolutions, we constructed the architecture of a geographic graph-level hybrid network to be a flexible inductive rather than transductive model for any unseen input data. Based on such a geography network, the convolutional kernel was also designed according to Tobler's law to encode a neighborhood feature through powerful embedding learning of the graph network [68]. In addition, full residual layers were concatenated with the graph convolution (GC) outputs to boost the learning and reduce over-smoothing deriving from graph convolutions. This paper showed robustness of the proposed geographic graph hybrid network for inversion of $\mathrm{PM}_{2.5}$ and $\mathrm{PM}_{10}$ in mainland China, and the proposed method can also be generalized to other similar geo-features that have strong spatial correlation and involve surrounding massive remote sensing data and other covariates.

\section{Materials and Methods}

\subsection{Study Area}

The study area of mainland China is located approximately between $18^{\circ}$ and $54^{\circ}$ north latitude and $73^{\circ}$ and $135^{\circ}$ east longitude, with a population of about 1.4 billion in 2016 and 9.6 million square kilometers (Figure 1). The complex climate in the study area is affected by monsoon circulation and topography variability. The average air temperature is about $9.6^{\circ} \mathrm{C}$, the average annual total solar radiation is about $5.6 \times 10^{3} \mathrm{MJ} / \mathrm{m}^{2}$, the average annual precipitation is about $629.9 \mathrm{~mm}$, the average relative humidity is about $68.0 \%$, and the average wind speed is about $1.9 \mathrm{~m} / \mathrm{s}$ [69-71]. The northerly wind blowing from the mainland to the ocean prevails in winter, and the southerly wind blowing from the ocean to the land prevails in summer [72]. Based on the reanalysis data [73], the study area has an average PBLH of about $591.9 \mathrm{~m}$ and an average cloud fraction of about $2.8 \%$.

Air pollution is a major environmental issue in mainland China as a result of increasing industrialization and complex climate. $\mathrm{PM}_{10}$ and $\mathrm{PM}_{2.5}$ are two typical air pollutants, especially in the winter of mainland China. $\mathrm{PM}_{2.5}$ mainly comes from combustion of gasoline, oil, diesel fuel or wood, cement production, etc. In addition to $\mathrm{PM}_{2.5}$ emission sources, $\mathrm{PM}_{10}$ also comes from dust from construction sites, landfills, agriculture, desert and atmospheric transportation [74], etc. In recent years, rigorous air-pollution controls have been taken to have a great effect in reduction of the $\mathrm{PM}_{2.5}$ levels in the atmosphere [75]. 


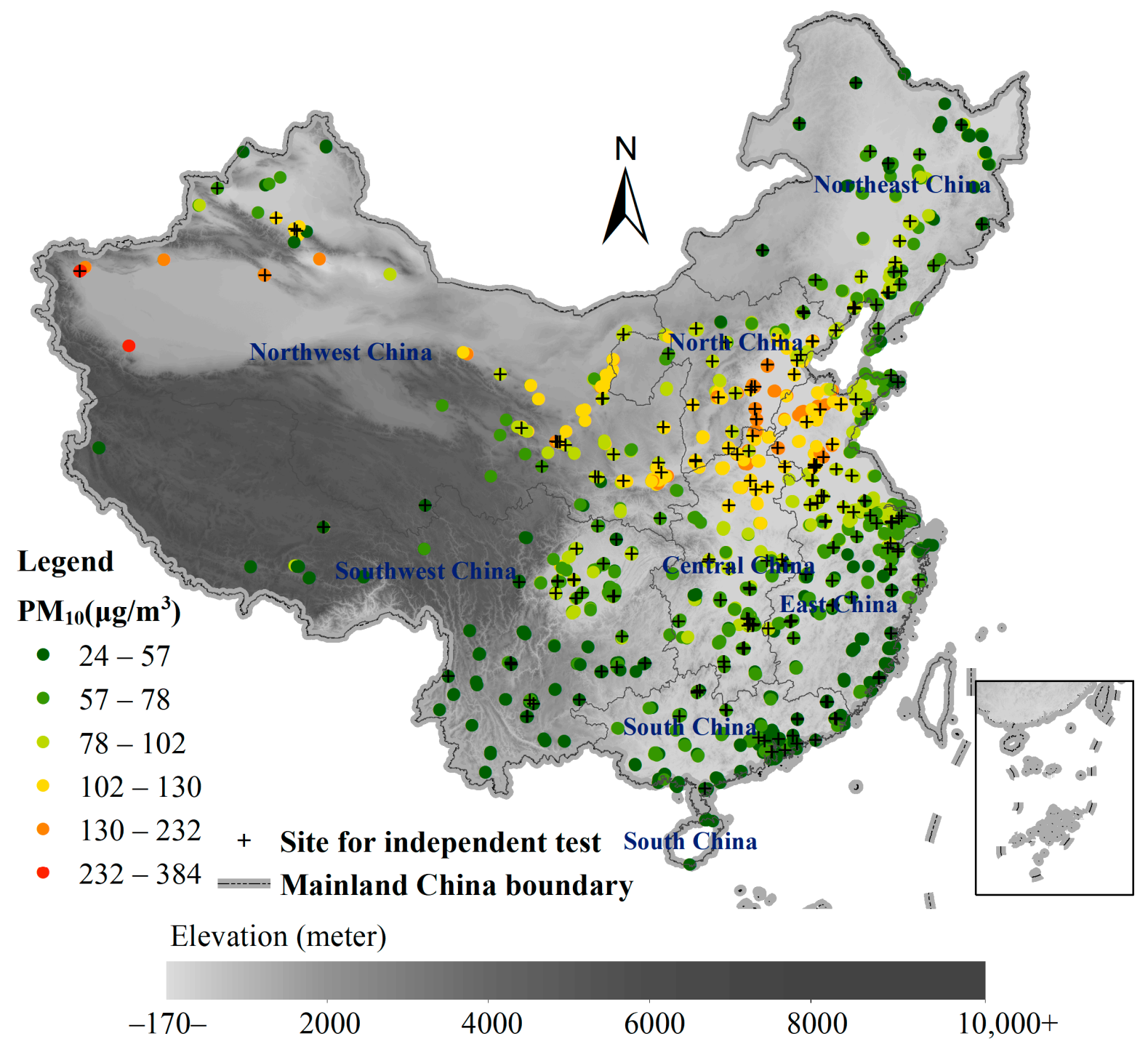

Figure 1. The study region of mainland China with seven geographic regions, and the PM monitoring sites and those selected for the site-based independent testing.

\subsection{Data}

2.2.1. PM Measurement Data

The hourly $\mathrm{PM}_{2.5}$ and $\mathrm{PM}_{10}$ measurement (unit: $\mu \mathrm{g} / \mathrm{m}^{3}$ ) data from 2015 to 2018 were gathered from 1594 monitoring sites of the China Environmental Monitoring Center (CNEMC) (http:/ / www.cnemc.cn, accessed on 10 March 2020). PM 2.5 and PM 10 concentrations were measured via beta attenuation, tapered element oscillating microbalance method (TEOM), or TEOM with a filter dynamics measurement system (FDMS) [76,77]. These TEOM monitors measured $\mathrm{PM}_{2.5}$ or $\mathrm{PM}_{10}$ depending on the sampling head installed. For more technical details of the PM monitors, please refer to [76,78].

The raw hourly $\mathrm{PM}_{2.5}$ and $\mathrm{PM}_{10}$ measurements were first preprocessed to remove invalid values and outliers caused by instrument malfunction and measurement errors [79]. Then, the daily averages were obtained from the valid hourly data. In total, 1,988,424 daily measurement samples for $\mathrm{PM}_{2.5}$ and $\mathrm{PM}_{10}$ were obtained for mainland China. The spatial distribution of these sampling locations with their means are also shown (including the independent testing sites) in Figure 1. 


\subsubsection{Remotely Sensed Data}

The advanced MAIAC AOD remote sensing data of 2015-2018 were collected from the NASA data sharing site (https: / / lpdaac.usgs.gov/products/mcd19a2v006, accessed on 18 March 2020). The daily data had a spatial resolution of $1 \times 1 \mathrm{~km}^{2}$. In this study, due to a high correlation (0.51 vs. 0.30$)$ with ground particulate matters, we also used the ground aerosol extinction coefficient (https: / / doi.org/10.7910/DVN/YDJT3L, accessed on 15 March 2021) [80], which was obtained by conversion from MAIAC AOD using planetary boundary layer height (PBLH) and relative humidity. The gaps of the MAIAC AOD data have been filled using powerful deep learning [81]. The normalized difference vegetation index (NDVI) and the enhanced vegetation index (EVI) $1 \mathrm{~km}$ data of 16-day intervals were obtained from NASA (https: / / modis.gsfc.nasa.gov/data/dataprod/mod13.php, accessed on 1 June 2020).

\subsubsection{Geographic Zone}

The geographic region datum (Figure 1) was obtained from the Resource Environmental Science and Data Centre, Chinese Academy of Sciences (http:/ / www.resdc.cn, accessed on 1 June 2020). There are seven zones for mainland China: Northeast China, Northwest China, North China, Southwest China, East China, Central China and South China. For PM modeling, the one-hot coding [82] was used to encode the region factor through seven binary ( 0 or 1 ) variables to include it in the model to account for the zonal variance in PMs.

\subsubsection{Reanalysis Data}

The coarse-resolution $\left(0.625^{\circ} \times 0.5^{\circ}\right)$ MERRA-2 Global Modeling Initiative data (MERRA-GMI) were obtained from https://portal.nccs.nasa.gov/datashare/merra2_gmi (accessed on 1 September 2020). The dataset was generated through the simulation for the atmospheric composition coupling MERRA2 meteorological variables with the Global Modeling Initiative (GMI)'s stratosphere-troposphere chemical mechanism. The simulation is interactively coupled to the Goddard Chemistry Aerosol Radiation and Transport module, with inclusion of similar emissions for MERRA-2 [83]. Overall, 15 modeled gaseous air pollutants and particulate matter source contributions of MERR2-GMI and 6 MERRA2 parameters were selected given their acceptable correlation (absolute correlation $\geq 0.01$ ). See Appendix A Table A1 for specific variables. In order to match the target spatial resolution $\left(1 \times 1 \mathrm{~km}^{2}\right)$, bilinear interpolation [84] was used as the resampling method to convert the coarse-resolution daily reanalysis data to fine-resolution data.

\subsubsection{High-Resolution Meteorology and the Other Data}

In addition to the reanalysis data, the high-resolution $(1 \mathrm{~km})$ surface meteorology data were also obtained from the high-resolution meteorological interpolation dataset of mainland China $[85,86]$. The full residual deep learning method [55] was used to interpolate the daily $1 \times 1 \mathrm{~km}^{2}$ grids of meteorological variables. In interpolation, the input variables included latitude, longitude, day of year, elevation, and meteorological reanalysis data (see [80] for technical details). The finely resolved dataset had high interpolation accuracy, which exactly matched the target spatial $(1 \mathrm{~km})$ and temporal (daily) resolution of this study. These high-resolution meteorology data included daily air pressure $(\mathrm{hPa})$, air temperature $\left({ }^{\circ} \mathrm{C}\right)$, relative humidity $(\%)$, and wind speed $(\mathrm{m} / \mathrm{s})$.

We also gathered the other spatial and temporal variables, including the coordinates ( $x$ and $y$ ) and their derivatives (squares of $x$ and $y$, and product of $x$ and $y$ ), elevation, multiscale time indices (day of year and natural month). The elevation datum of $500 \mathrm{~m}$ resolution was obtained from Shuttle Radar Topology Mission (SRTM, https: / www2.jpl. nasa.gov/srtm, accessed on 1 March 2019). 


\subsection{Methods}

\subsubsection{Preprocessing}

The preprocessing included data cleaning, resampling, temporal alignment and normalization. Data cleaning was to remove noisy input data and improve model training. Here, the loose outer fence [87] was defined as (mean $-5 \times \mathrm{IQR}$, mean $+5 \times \mathrm{IQR}$ ) (IQR: interquartile range) to filter out those noise or invalid measurement or covariate data that are not within the normal range. Due to complex meteorology and atmospheric chemical transmission, $\mathrm{PM}_{2.5}$ and $\mathrm{PM}_{10}$ may occasionally have extreme concentration values, so the $\mathrm{PM}$ measurement data may cover a relatively high value range $[88,89]$. Therefore, the loose intervals were defined here to remove noisy data [90]. A bilinear interpolation method was used to resample the data at different spatial and/or temporal resolutions into the standard target spatial $\left(1 \times 1 \mathrm{~km}^{2}\right)$ and temporal (daily) resolution data. Temporal alignment was used to match the data at different temporal resolutions (e.g., hourly, monthly and yearly) into daily resolution data. For estimation of $\mathrm{PM}_{2.5}$ and $\mathrm{PM}_{10}$, log transformation was conducted to make them normally distributed. For deep learning, standard normalization [91] was conducted for the log-transformed $\mathrm{PM}$ variables $\left(\mathrm{PM}_{2.5}\right.$ and $\left.\mathrm{PM}_{10}\right)$ and each covariate to make them have a standard normal distribution (mean: 0; standard deviation: 1 ). The PM normalization parameters were also used for the inverse normalization of the outputs so that they are converted back to the original value range.

\subsubsection{Geographic Graph Network}

The geographic graph network is defined as a graph-level neural network $(\mathcal{G})$ in a geographic coordinate system, where each node corresponds to a spatial location or spatiotemporal point for the vector dataset, or one cell for the grid dataset:

$$
\mathcal{G}=(\mathcal{V}, \mathcal{E}), \forall \mathcal{V} \in \mathcal{C}
$$

where $\mathcal{V}$ represents the set of graph nodes, $\mathcal{E}$ represents the set of edges connecting the nodes and $\mathcal{C}$ is the geographic coordinate or spatiotemporal coordinate system.

Unlike the general graph neural network [92], where the connections between nodes can be determined manually or learned by learning through all the features, we can construct a geographic graph network according to Tobler's First Law of Geography: "everything is related to everything else, but near things are more related than distant things" [93]. The $k$ nearest neighbor $(k-\mathrm{NN})$ method can be used to retrieve $k$ nearest neighbors based on geographic coordinates to construct a geographic graph neural network. As shown in Figure 2a, a target node can be linked with $k$ immediate (one-hop) nearest neighbors to form a small local graph; then, each of the target node's neighbors can also be linked to its nearest neighbors (two hops). Thus, a small local graph of two levels can be formed by the target node and its one-hop and two-hop neighbors. Recursively, a small local graph of three or more levels can be constructed for the target node. Such multilevel interconnected nodes of all the target nodes make up a local geographic graph network.

For construction of a geographic spatiotemporal graph, the spatial coordinates and the time index first need to be normalized to be unitless. Thus, the spatiotemporal distance can be calculated based on normalized coordinates and temporal index, and $k-\mathrm{NN}$ can be used to retrieve $k$ nearest nodes based on such spatiotemporal distances. As shown in Figure 2b, the nodes of three temporal slices $(T-1, T$ and $T+1)$ are used to retrieve nearest one-hop nodes for the target node in $T$ (red square in Figure 2(II)). Similarly, the two or more hop neighbors for the target node can be retrieved recursively. Such interconnected multilevel neighbors form a small graph for the target node. All the interconnected nodes for all the target nodes make up a local spatiotemporal geographic graph network. Different from GraphSAGE [65], we limit the features used in $k$-NN to spatial coordinates or normalized spatiotemporal features. 


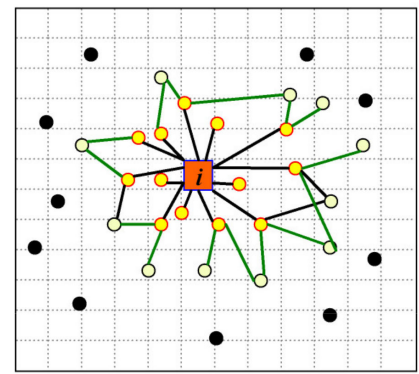

The $i^{\text {th }}$ target location or cell (one node)

o One-hop nearest node for the target node

o Two-hop nearest node for the target node

- One-hop spatial link

- Two-hop spatial link

a. $k$ nearest spatial neighbors (locations) for a target node (central red cell)

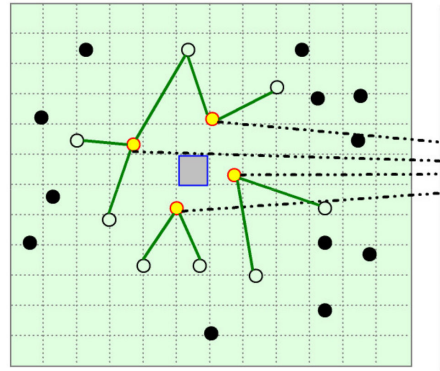

I. $T-1$

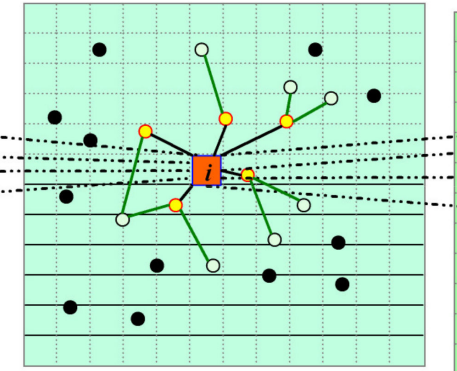

II. $T$

-..... One-hop spatiotemporal link

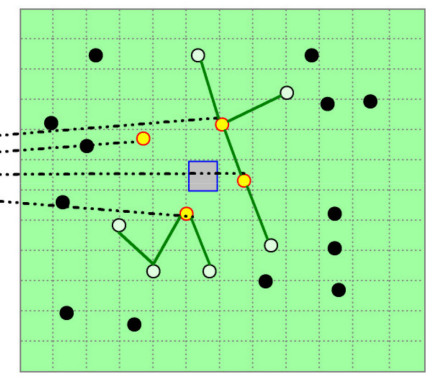

II. $T+1$

b. $k$ nearest spatiotemporal neighbors (locations) for a target node (central red cell)

Figure 2. Construction of geographical graph (a) and geographical spatiotemporal graph (b) using $k$-NN.

Based on Tobler's First Law of Geography, we defined the mean aggregate operator weighted by the reciprocal of spatial or spatiotemporal distance as:

$$
\mathbf{h}_{\mathcal{N}(i)}^{k}=m_{d_{\mathcal{N}(i)}}\left(\left\{\mathbf{h}_{j}^{k-1}, \forall j \in \mathcal{N}(i)\right\}\right)=\frac{\sum_{j=1}^{|\mathcal{N}(u)|} \frac{1}{d_{i j}} \mathbf{h}_{j}^{k-1}}{\sum_{j=1}^{|\mathcal{N}(u)|} \frac{1}{d_{i j}}}
$$

where $i$ represents the index of the target node, $\mathcal{N}(i)$ denotes the set of the nearest neighbors for $i, \mathbf{h}_{\mathcal{N}(i)}^{k}$ represents the generalized neighborhood feature of the $k$ th graph convolution for $i, \mathbf{h}_{j}^{k-1}$ denotes the output of the $j$ th neighbor node of the $k-1$ graph convolution, $d_{i j}$ is the spatial or spatiotemporal distance between $i$ and $j, m_{d_{\mathcal{N}(i)}}$ denotes the function of weighted mean, $k=1,2, \ldots, \mathcal{K}, \mathcal{K}$ is the number of graph convolutions (the number of hops).

Then, the update function of the $k$ th convolution layer is defined as:

$$
\mathbf{h}_{i}^{k}=\mathrm{BN}\left(\sigma\left(\mathbf{W}_{l}^{k} \cdot \mathbf{h}_{\mathcal{N}(i)}^{k}+\mathbf{W}_{r}^{k} \cdot \mathbf{h}_{i}^{k-1}\right)\right)
$$

where $\mathbf{h}_{i}^{k-1}$ represents the output of the $k-1$ th convolution, $\sigma$ is the activation function (Rectified Linear Unit, ReLU), BN denotes batch normalization, $\mathbf{W}_{l}^{k}$ and $\mathbf{W}_{r}^{k}$ represent the parameter matrices of $\mathbf{h}_{\mathcal{N}(i)}^{k}$ and $\mathbf{h}_{i}^{k-1}$, respectively. The last convolution has the 1-d output that represents the generalized neighborhood feature.

The algorithm of the geographic graph convolution minibatch forward is presented in Algorithm 1. The mean aggregator is almost equivalent to the convolutional messaging and propagation used in the fixed transductive graph convolution [94]. By introducing the weights of the distance reciprocal, linear transformation is conducted for the mean aggregator. This weighted convolutional aggregator is a rough, linear approximation of a localized spectral convolution. Through powerful embedding learning, this convolution is appropriate to capture spatial or spatiotemporal correlation features from the neighborhood data. 


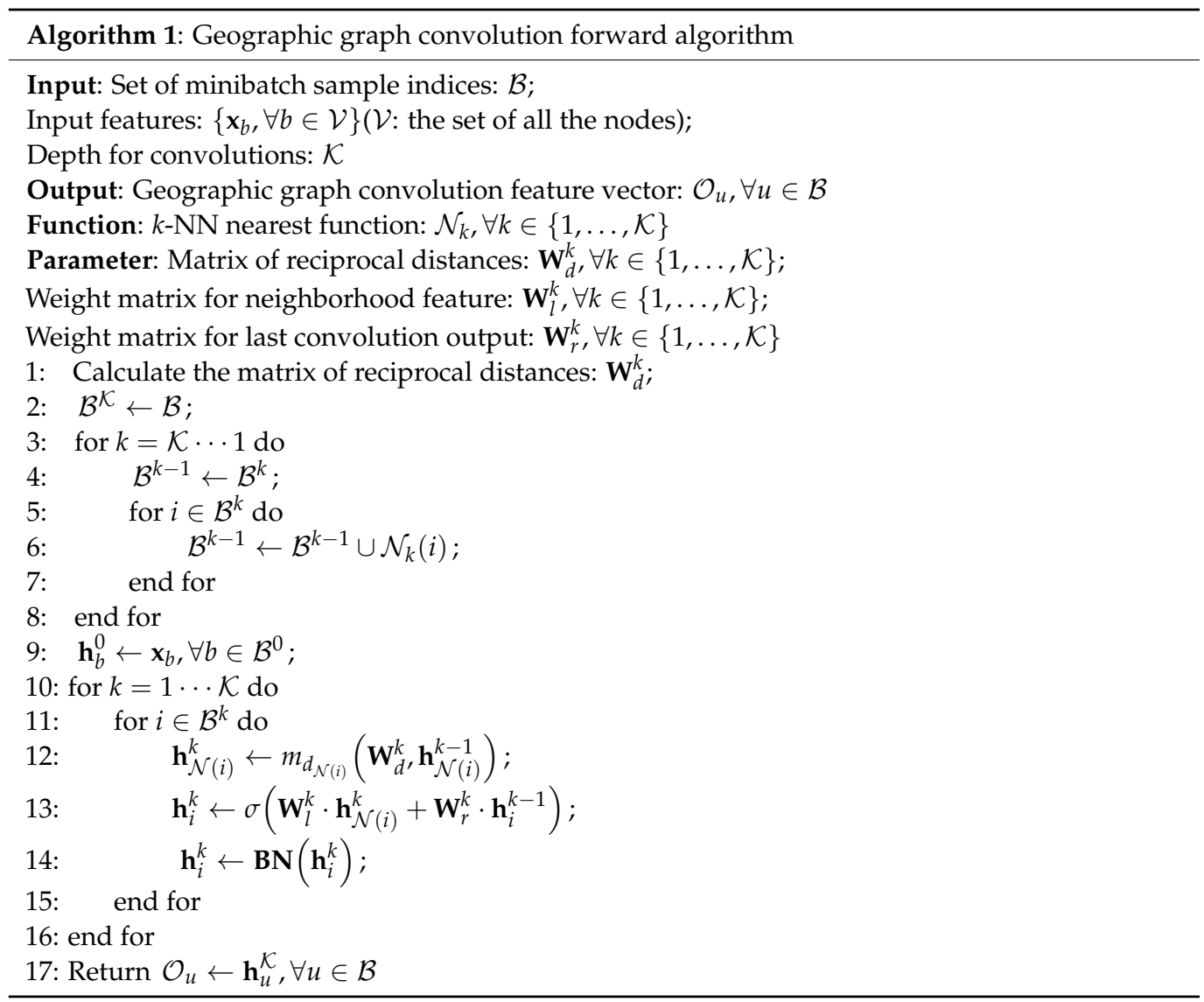

\subsubsection{Concatenating with Full Residual Layers}

In order to reduce the potential overfitting issue by graph convolutions [95], a graph hybrid network architecture is constructed (Figure 3). Here, the output of graph convolutions is concatenated with the original input as the input of a full residual deep encoder-decoder [55]. The full residual deep network has a strong learning ability through full residual connections between the encoders and the decoders [81,96], and can strengthen the representation learning of features, thus reducing the overfitting in graph neighborhood learning. The full residual deep encoder-decoder has a symmetric network topology and consists of the input layer, encoding layers, a coding layer, decoding layers and the output layer. Each encoding layer has a corresponding decoding layer with the same number of nodes and a residual link is connected between them to enhance backpropagation of the error information through shortcuts in learning. For air pollution modeling, the sensitivity analysis of different network topologies (different layers and nodes for each layer) showed that the network topology with the number of nodes $(512,265,128,64,32,16,8,16,32,64$, $128,256,512)$ had good performance, which was measured by the high performance score in the test dataset. 


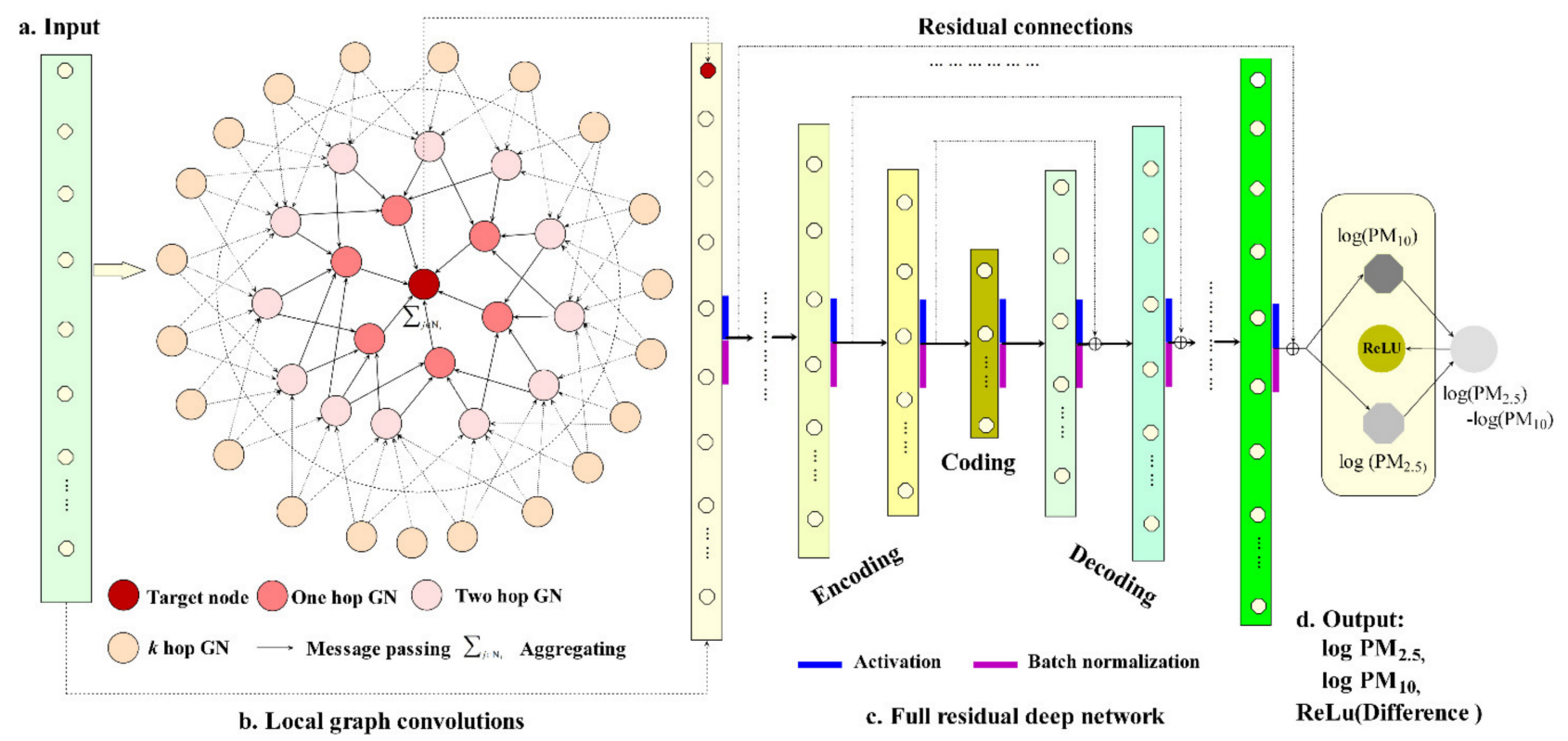

Figure 3. Systematic architecture of geographic (spatiotemporal) graph hybrid network.

\subsubsection{Parameter Sharing Output Subject to the Relationship Constraint}

As part of $\mathrm{PM}_{10}$, the concentration of $\mathrm{PM}_{2.5}$ is always equal to or lower than that of $\mathrm{PM}_{10}$. In addition to the emission sources of $\mathrm{PM}_{2.5}, \mathrm{PM}_{10}$ also comes from desert and construction dust, agriculture and atmospheric transformation. In order to make the model distinguish $\mathrm{PM}_{2.5}$ and $\mathrm{PM}_{10}$ well, we trained a model to predict the concentrations of $\mathrm{PM}_{2.5}$ and $\mathrm{PM}_{10}$ at the same time. Through parameter sharing and specification, the trained model has good generalization and the ability to distinguish between $\mathrm{PM}_{2.5}$ and $\mathrm{PM}_{10}$. In addition, the $\mathrm{PM}_{2.5}-\mathrm{PM}_{10}$ relationship constraint is encoded in the loss function, so that the model can make reasonable predictions for $\mathrm{PM}_{2.5}$ and $\mathrm{PM}_{10}$. The loss function is defined as:

$$
L\left(\theta_{\mathbf{W}, \mathbf{b}}\right)=\frac{1}{N} \uparrow_{R S E}\left(C_{\mathrm{PM}_{2.5}}, f_{\mathrm{PM}_{2.5}}(\mathbf{x})\right)+\frac{1}{N} \uparrow_{R S E}\left(C_{\mathrm{PM}_{10}}, f_{\mathrm{PM}_{10}}(\mathbf{x})\right)+\lambda_{r} e_{r}
$$

where $C_{\mathrm{PM}_{2.5}}$ and $C_{\mathrm{PM}_{2.5}}$ represent the observed concentrations or their transformations (log-transformed and normalized) of $\mathrm{PM}_{2.5}$ and $\mathrm{PM}_{10}$, respectively, $\uparrow_{R S E}$ is the RSE loss function, $f_{\mathrm{PM}_{2.5}}$ and $f_{\mathrm{PM}_{10}}$ is the prediction functions for the transformations of $\mathrm{PM}_{2.5}$ and $\mathrm{PM}_{10}$, respectively, $N$ is the number of training samples, and $\lambda_{r}$ is the weight (defined as a value between 0 and 1 , usually determined through sensitivity analysis) for $e_{r}$, that is the constraint term of the relationship between $\mathrm{PM}_{2.5}$ and $\mathrm{PM}_{10}\left(\mathrm{PM}_{2.5} \leq \mathrm{PM}_{10}\right)$ for the prediction:

$$
e_{r}=\frac{1}{N} \uparrow R S E\left(\operatorname{ReLU}\left(f_{\mathrm{PM}_{2.5}}(\mathbf{x})-f_{\mathrm{PM}_{10}}(\mathbf{x})\right)\right)
$$

that can be interpreted as: if $f_{\mathrm{PM}_{2.5}}(\mathbf{x})>f_{\mathrm{PM}_{10}}(\mathbf{x}), e_{r}>0$ will lead to an increase in the loss, which in turn propagates back to change the parameters, thus making the loss smaller during the gradient descent optimization. By encoding (5) in the loss function, the trained model tries to maintain a reasonable relationship $\left(\mathrm{PM}_{2.5} \leq \mathrm{PM}_{10}\right)$ when making predictions.

\subsection{Evaluation}

In order to evaluate the proposed method, regular stratified validation and a sitebased independent test were conducted. For the site-based independent test, about $15 \%$ of the monitoring sites were selected through stratified sampling for independent testing and the remaining $85 \%$ sites were used for regular training and testing (Figure 1). Here, the geographic zone datum of mainland China was used as the stratifying factor; the seven 
geographic regions (zones) were shown in Figure 1. Any samples from the sites of the independent test were not used for model training, but only for the independent testing.

The regional and seasonal indices were used as the combinational stratifying factor for sampling in regular validation. The seasonal index was defined as spring (March, April and May), summer (June, July and August), autumn (September, October and November) and winter (December, January and February). Of all the samples of the $85 \%$ monitoring sites, $68 \%$ were used for model training and the other $32 \%$ were used for regular testing.

The performance metrics included R-squared $\left(\mathrm{R}^{2}\right)$ and root mean square error (RMSE) between predicted values and observed values. The training, testing and independent testing metrics were reported for $\mathrm{PM}_{2.5}$ and $\mathrm{PM}_{10}$, respectively. Compared with testing in cross-validation, the site-based independent testing can better show the actual generalization or extrapolation accuracy of the trained models. From all the samples, we selected 20 datasets of different training and test samples using bootstrap sampling, and each set of samples was used to train a model. A total of 20 models were trained using 20 sets of samples, and their average performance metrics were summarized.

\section{Results}

3.1. Descriptive Statstics of $P M_{2.5}$ and $P M_{10}$ and Critical Covariates

3.1.1. Summary of Daily $\mathrm{PM}_{2.5}$ and $\mathrm{PM}_{10}$

From 2015 to 2019, we collected 1,988,424 daily samples of $\mathrm{PM}_{2.5}$ and $\mathrm{PM}_{10}$ from 1594 monitoring sites. According to the land cover classification data of urban and rural regions (http:/ / data.ess.tsinghua.edu.cn, accessed on 1 July 2021) [97], of these monitoring sites, 864 were from urban areas and the other 730 were from rural areas. For the daily samples (Table 1), the mean was $46.8 \mu \mathrm{g} / \mathrm{m}^{3}$ for $\mathrm{PM}_{2.5}$ and $83.0 \mu \mathrm{g} / \mathrm{m}^{3}$ for $\mathrm{PM}_{10}$, and the standard deviation was $39.6 \mu \mathrm{g} / \mathrm{m}^{3}$ for $\mathrm{PM}_{2.5}$ and $74.8 \mu \mathrm{g} / \mathrm{m}^{3}$ for $\mathrm{PM}_{10}$. North China and Central China had the highest mean $\mathrm{PM}_{2.5}\left(57.2-58.8 \mu \mathrm{g} / \mathrm{m}^{3}\right)$, and North China and Northwest China had the highest mean $\mathrm{PM}_{10}\left(109.3-110.5 \mu \mathrm{g} / \mathrm{m}^{3}\right)$. South China and Southwest China had the lowest mean $\mathrm{PM}_{2.5}$ and $\mathrm{PM}_{10}$. Supplementary Table S1 also showed the descriptive statistics of the meteorological covariates of the monitoring sites involved in the modeling.

Table 1. Mean and regional means of $\mathrm{PM}_{2.5}$ and $\mathrm{PM}_{10}$ for 2015-2018 in mainland China.

\begin{tabular}{|c|c|c|c|c|c|c|c|c|c|}
\hline Pollutant & $\begin{array}{c}\text { Statistics } \\
\left(\mu \mathrm{g} / \mathrm{m}^{3}\right)\end{array}$ & $\begin{array}{c}\text { Mainland } \\
\text { China }\end{array}$ & $\begin{array}{c}\text { Northeast } \\
\text { China }\end{array}$ & $\begin{array}{l}\text { North } \\
\text { China }\end{array}$ & $\begin{array}{c}\text { East } \\
\text { China }\end{array}$ & $\begin{array}{c}\text { Central } \\
\text { China }\end{array}$ & $\begin{array}{l}\text { South } \\
\text { China }\end{array}$ & $\begin{array}{c}\text { Northwest } \\
\text { China }\end{array}$ & $\begin{array}{c}\text { Southwest } \\
\text { China }\end{array}$ \\
\hline \multirow{4}{*}{$\mathrm{PM}_{2.5}$} & Mean & 46.8 & 41.9 & 58.8 & 47.9 & 57.2 & 33.7 & 48.7 & 36.9 \\
\hline & Median & 36.0 & 31.0 & 45.0 & 39.0 & 46.0 & 28.0 & 35.0 & 29.0 \\
\hline & $\begin{array}{l}\text { Standard } \\
\text { deviation }\end{array}$ & 39.6 & 38.6 & 50.0 & 34.9 & 43.2 & 22.0 & 50.2 & 20.2 \\
\hline & IQR & 36.0 & 33.0 & 46.0 & 35.0 & 41.0 & 25.0 & 35.0 & 30.0 \\
\hline \multirow{4}{*}{$\mathrm{PM}_{10}$} & Mean & 83.0 & 72.5 & 110.5 & 81.2 & 95.6 & 53.3 & 109.3 & 52.0 \\
\hline & Median & 66.0 & 58.0 & 91.0 & 68.0 & 80.0 & 46.0 & 80.0 & 42.5 \\
\hline & $\begin{array}{l}\text { Standard } \\
\text { deviation }\end{array}$ & 74.8 & 56.0 & 78.6 & 68.5 & 63.4 & 30.0 & 134.6 & 42.5 \\
\hline & IQR & 36.0 & 52.0 & 78.0 & 58.0 & 67.0 & 33.0 & 75.0 & 46.0 \\
\hline Ratio & Mean & 0.57 & 0.57 & 0.53 & 0.60 & 0.60 & 0.62 & 0.47 & 0.58 \\
\hline$\left(\mathrm{PM}_{2.5} / \mathrm{PM}_{10}\right)$ & IQR & 0.24 & 0.26 & 0.25 & 0.22 & 022 & 0.19 & 0.25 & 0.23 \\
\hline
\end{tabular}

From these daily samples, 283,719 samples were selected based on the stratified regional factor (seven geographic regions in Figure 1) from 230 sites for the site-based independent test. From the remaining samples, 1,159,199 were selected using the combinational stratifying factor of region and season for model training and 545,506 were used for testing in validation. 


\subsubsection{Selection of Significant Covariates}

Correlation analysis was conducted for $\mathrm{PM}_{2.5} / \mathrm{PM}_{10}$ and covariates. The absolute Pearson correlation of 0.01 was used to filter out the less useful covariates. In total, 35 covariates were selected as the model input from 41 candidate covariates (Figure 4 for their correlation and units). These covariates included four meteorology (air temperature, wind speed, air pressure, relative humidity), two aerosol covariates (MAIAC AOD and ground aerosol coefficient), NDVI and enhanced vegetation index (EVI), six MERRA2 variables (ozone, cloud fraction, $\mathrm{PBLH}, \mathrm{AOD}$, wind stagnation and mixing), an Aura ozone monitoring instrument (OMI) $\mathrm{NO}_{2}$, fifteen MERRA-GMI variables (daily satellite overpass fields: nitric oxide $(\mathrm{NO})$, ozone $\left(\mathrm{O}_{3}\right)$, carbon monoxide $(\mathrm{CO}), \mathrm{NO}_{2}$, sulfur dioxide $\left(\mathrm{SO}_{2}\right)$; aerosol diagnostics: organic carbon surface mass concentration, black carbon surface mass concentration, dust surface mass concentration- $\mathrm{PM}_{2.5}$, nitrate surface mass concentration $\mathrm{PM}_{2.5}, \mathrm{SO}_{2}$, nitric acid surface mass concentration; bottom layer diagnostics: $\mathrm{NO}_{2}, \mathrm{NO}, \mathrm{PM}$, $\left.\mathrm{PM}_{25}\right)$, latitude and longitude, land-use areal proportion, and two traffic variables.
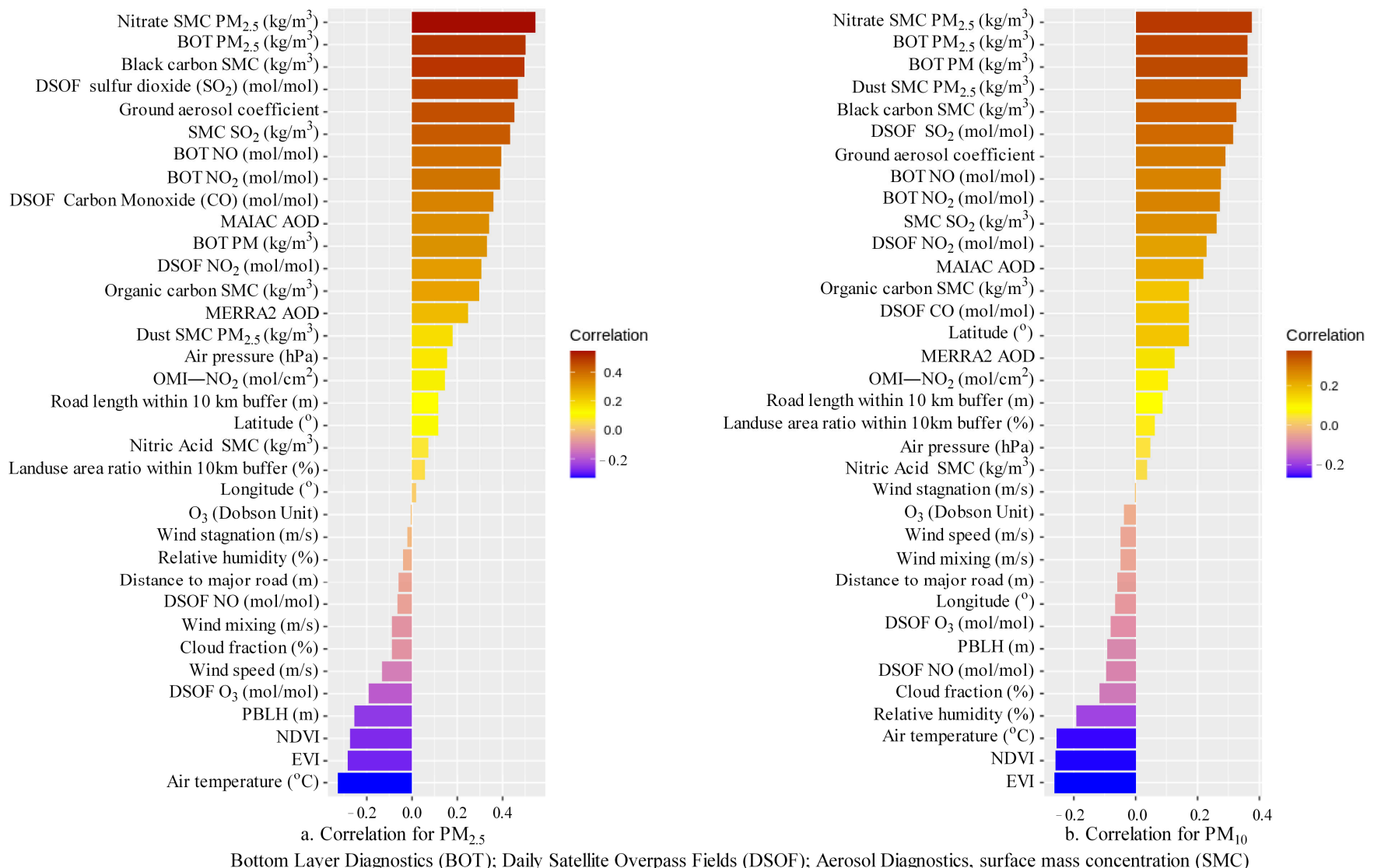

Figure 4. Bar plots of Pearson's correlation for selection of the covariates ((a) for $\mathrm{PM}_{2.5}$ and (b) for $\left.\mathrm{PM}_{10}\right)$.

\subsection{Modeling Performance}

The total loss (Equation (4)) included $\mathrm{PM}_{2.5}$ loss, $\mathrm{PM}_{10}$ loss, and the $\mathrm{PM}_{2.5}-\mathrm{PM}_{10}$ relationship loss. The learning curves of total loss, $\mathrm{PM}_{2.5}$ loss and $\mathrm{PM}_{10}$ loss showed a gradual downward trend (Figure 5). Especially as the learning progressed, the relationship loss curve approached zero, indicating that the physical relationship of $\mathrm{PM}_{2.5} \leq \mathrm{PM}_{10}$ was maintained during the learning process. The learning curve of $\mathrm{R}^{2}$ and RMSE in training, testing and site-based independent testing (Figure 6) showed a trend of learning convergence. The sample size of the training dataset was very large $(1,159,199)$, so a large number of learning epochs (250) was selected to ensure sufficient learning in the dataset to obtain a stable convergence state. After 250 learning epochs, the learning curve was 
approaching an optimal solution for the model. Through sensitivity analysis, we obtained the optimal solutions for the other hyperparameters, including a minibatch size of 2048, a learning rate of 0.01 and $\lambda_{r}$ of 0.5 , respectively.
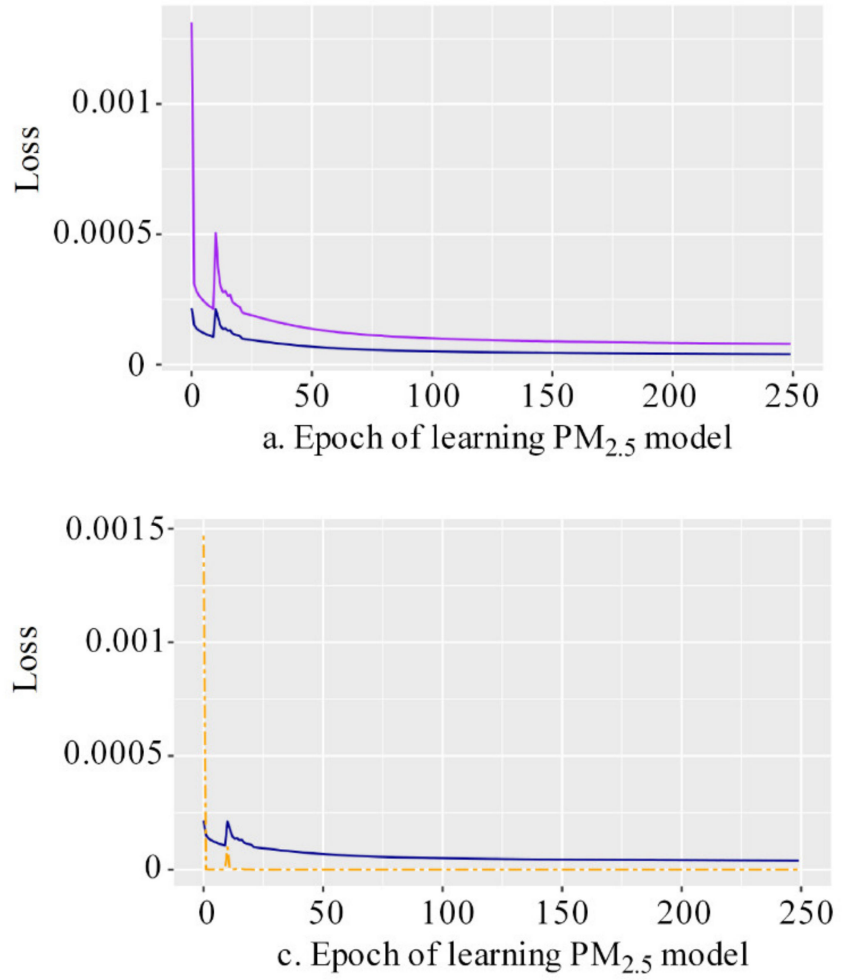

Total loss curve - Loss of $\mathrm{PM}_{2.5}$

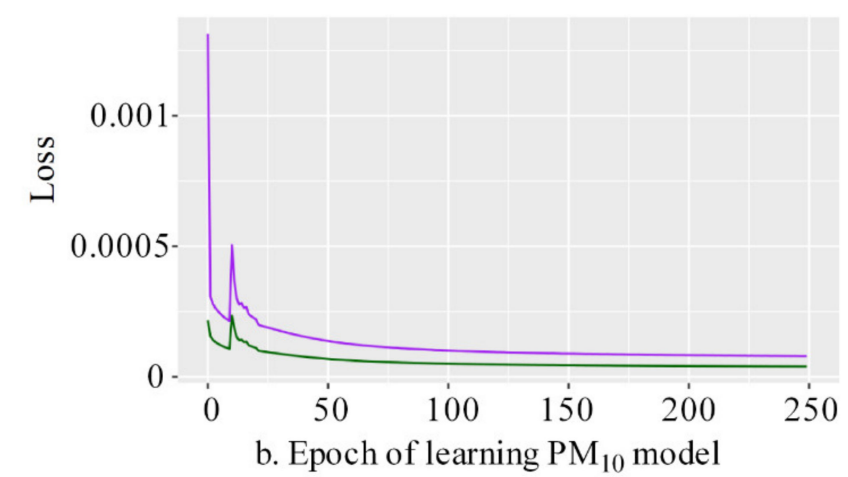

0.0015

in 0.001

0.0005

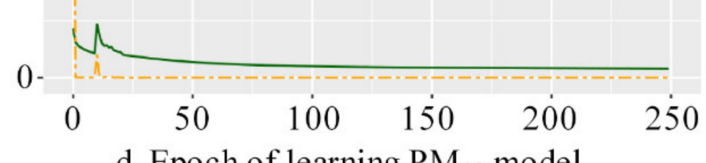

d. Epoch of learning $\mathrm{PM}_{10}$ model

Loss of the $\mathrm{PM}_{2.5}-\mathrm{PM}_{10}$ relationship

Figure 5. Curves of total loss, $\mathrm{PM}_{2.5}$ loss $(\mathbf{a}, \mathbf{c})$ and $\mathrm{PM}_{10}$ loss (b,d) and the loss of $\mathrm{PM}_{2.5}-\mathrm{PM}_{10}$ relationship (c,d).
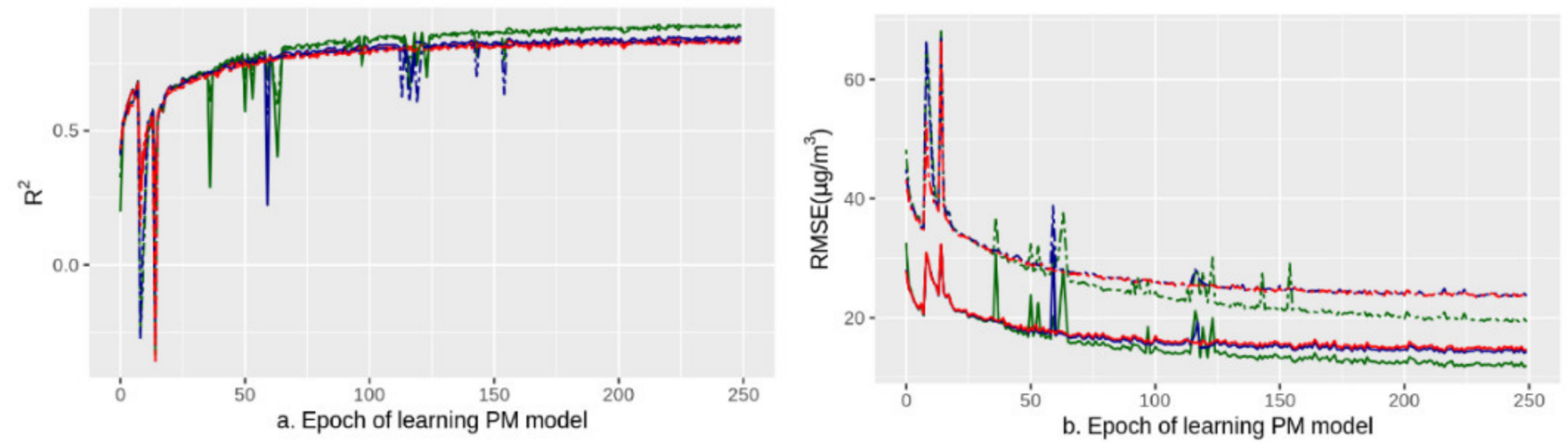

Training curve for $\mathrm{PM}_{2.5} \longrightarrow$ Testing curve for $\mathrm{PM}_{2.5}$

Independent testing curve for $\mathrm{PM}_{2.5}$

Training curve for $\mathrm{PM}_{10} \ldots \ldots$. Testing curve for $\mathrm{PM}_{10}$ Independent testing curve for $\mathrm{PM}_{10}$

Figure 6. Curves of training, testing and site-based independent testing for $\mathrm{R}^{2}$ (a) and RMSE (b).

The optimal model was trained using the proposed method (Table 2): training $\mathrm{R}^{2}$ of 0.91 , testing $R^{2}$ of $0.84-0.85$ and site-based independent testing $R^{2}$ of $0.82-0.83$; training RMSE of $9.82 \mu \mathrm{g} / \mathrm{m}^{3}$ for $\mathrm{PM}_{2.5}$ and $17.02 \mu \mathrm{g} / \mathrm{m}^{3}$ for $\mathrm{PM}_{10}$, testing RMSE of $13.87 \mu \mathrm{g} / \mathrm{m}^{3}$ for $\mathrm{PM}_{2.5}$ and $23.54 \mu \mathrm{g} / \mathrm{m}^{3}$ for $\mathrm{PM}_{10}$ and site-based independent testing RMSE of $14.51 \mu \mathrm{g} / \mathrm{m}^{3}$ for $\mathrm{PM}_{2.5}$ and $24.34 \mu \mathrm{g} / \mathrm{m}^{3}$ for $\mathrm{PM}_{10}$. The scatter plots between observed values and predicted values in the site-based independent testing (Figure 7) showed that most of 
the variance was captured by the trained model with few outliers. The scatter plot of observations and residuals (Figure 8) showed a slight underestimation of extreme high values, which was normal for most regression models due to data measurement errors and modeling uncertainties [98]. The residuals presented normal distribution (Figure 9), and their averages were close to zero, indicating minimal bias in the independent test. The average SHapley Additive exPlanations (SHAP) $[99,100]$ score of each covariate was summarized as a measure of feature importance (Supplementary Figure S1). Given that the proposed GGHN was a nonlinear modeling method, Pearson's linear correlation between each covariate and the target variable $\left(\mathrm{PM}_{2.5}\right.$ or $\left.\mathrm{PM}_{10}\right)$ could not quantify such a nonlinear relationship. Compared with Pearson's correlation, the SHAP value better quantified the contribution of each covariate to the predictions.

Compared with other seven typical methods including a full residual deep network, local graph convolution network, random forest, XGBoost, regression kriging, kriging and a generalized additive model, the proposed geographic graph hybrid network improved test $\mathrm{R}^{2}$ by $5-57 \%$ for $\mathrm{PM}_{2.5}$ and $4-87 \%$ for $\mathrm{PM}_{10}$, and independent test $\mathrm{R}^{2}$ by $8-57 \%$ for $\mathrm{PM}_{2.5}$ and $8-78 \%$ for $\mathrm{PM}_{10}$; correspondingly, it decreased test RMSE by $11-49 \%$ for $\mathrm{PM}_{2.5}$ and 6-61\% for $\mathrm{PM}_{10}$, and independent test RMSE by $14-46 \%$ for $\mathrm{PM}_{2.5}$ and $15-48 \%$ for $\mathrm{PM}_{10}$. Especially, although GGHN had training $\mathrm{R}^{2}$ (0.91 vs. $0.92-0.94$ ) similar to or slightly lower than that of a full residual deep network and random forest, it had considerably better testing and independent testing $R^{2}(0.82-0.85$ vs. $0.71-0.81)$ and RMSE $\left(13.87-14.51 \mu \mathrm{g} / \mathrm{m}^{3}\right.$ vs. $15.51-17.63 \mu \mathrm{g} / \mathrm{m}^{3}$ for $\mathrm{PM}_{2.5} ; 23.54-24.34 \mu \mathrm{g} / \mathrm{m}^{3}$ vs. $24.98-30.34 \mu \mathrm{g} / \mathrm{m}^{3}$ for $\mathrm{PM}_{10}$ ), which indicated more improvement in generalization and extrapolation than the two methods. Compared with generalized additive model (GAM), the proposed geographic graph hybrid network achieved the maximum improvement in testing $\left(R^{2}\right.$ by $57 \%$ for $\mathrm{PM}_{2.5}$ and $87 \%$ for $\mathrm{PM}_{10}$ ) and independent testing $\left(\mathrm{R}^{2}\right.$ by $57 \%$ for $\mathrm{PM}_{2.5}$ and $78 \%$ for $\left.\mathrm{PM}_{10}\right)$.

Table 2. Training, testing and site-based independent testing for $\mathrm{PM}_{2.5}$ and $\mathrm{PM}_{10}$.

\begin{tabular}{|c|c|c|c|c|c|}
\hline \multirow{2}{*}{ Method } & \multirow{2}{*}{ Type } & \multicolumn{2}{|c|}{$\mathbf{P M}_{2.5}$} & \multicolumn{2}{|r|}{$\mathbf{P M}_{10}$} \\
\hline & & $\mathbf{R}^{2}$ & $\operatorname{RMSE}\left(\mu \mathrm{g} / \mathrm{m}^{3}\right)$ & $\mathbf{R}^{2}$ & $\operatorname{RMSE}\left(\mu \mathrm{g} / \mathrm{m}^{3}\right)$ \\
\hline \multirow{3}{*}{$\begin{array}{l}\text { Geographic graph hybrid } \\
\text { network (GGHN) }\end{array}$} & Training & 0.91 & 9.82 & 0.91 & 17.02 \\
\hline & Testing & 0.85 & 13.87 & 0.84 & 23.54 \\
\hline & Site-based independent testing & 0.83 & 14.51 & 0.82 & 24.34 \\
\hline \multirow{3}{*}{$\begin{array}{l}\text { Full residual } \\
\text { deep network }\end{array}$} & Training & 0.92 & 9.71 & 0.92 & 16.23 \\
\hline & Testing & 0.81 & 15.51 & 0.81 & 24.98 \\
\hline & Site-based independent testing & 0.72 & 17.63 & 0.71 & 30.34 \\
\hline \multirow{3}{*}{ Local GNN } & Training & 0.67 & 20.46 & 0.68 & 33.38 \\
\hline & Testing & 0.66 & 20.72 & 0.65 & 33.39 \\
\hline & Site-based independent testing & 0.65 & 20.98 & 0.65 & 33.78 \\
\hline \multirow{3}{*}{ Random forest } & Training & 0.94 & 9.31 & 0.94 & 14.95 \\
\hline & Testing & 0.79 & 17.34 & 0.78 & 28.87 \\
\hline & Site-based independent testing & 0.77 & 16.35 & 0.76 & 28.56 \\
\hline \multirow{3}{*}{ XGBoost } & Training & 0.68 & 20.89 & 0.65 & 34.78 \\
\hline & Testing & 0.67 & 21.56 & 0.65 & 35.78 \\
\hline & Site-based independent testing & 0.66 & 21.69 & 0.62 & 35.45 \\
\hline \multirow{3}{*}{ Regression kriging } & Training & - & - & - & - \\
\hline & Testing & 0.70 & 19.23 & 0.71 & 30.41 \\
\hline & Site-based independent testing & 0.72 & 18.76 & 0.70 & 30.03 \\
\hline \multirow{3}{*}{ Kriging } & Training & - & & - & - \\
\hline & Testing & 0.55 & 22.98 & 0.56 & 37.78 \\
\hline & Site-based independent testing & 0.55 & 22.65 & 0.55 & 38.45 \\
\hline \multirow{3}{*}{$\begin{array}{l}\text { Generalized additive } \\
\text { model }\end{array}$} & Training & 0.54 & 27.41 & 0.42 & 57.92 \\
\hline & Testing & 0.54 & 27.34 & 0.45 & 59.67 \\
\hline & Site-based independent testing & 0.53 & 26.89 & 0.46 & 47.13 \\
\hline
\end{tabular}



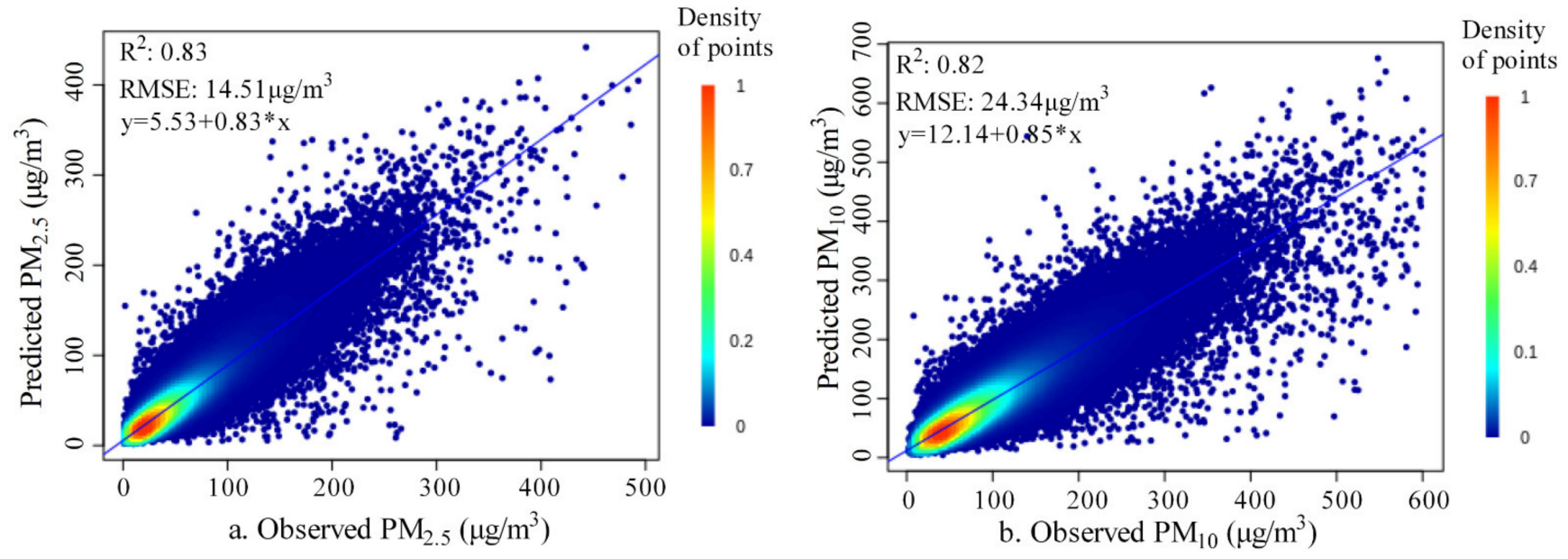

Figure 7. Scatter plots between observed values and predicted values ((a) for $\mathrm{PM}_{2.5} ;(\mathbf{b})$ for $\left.\mathrm{PM}_{10}\right)$.
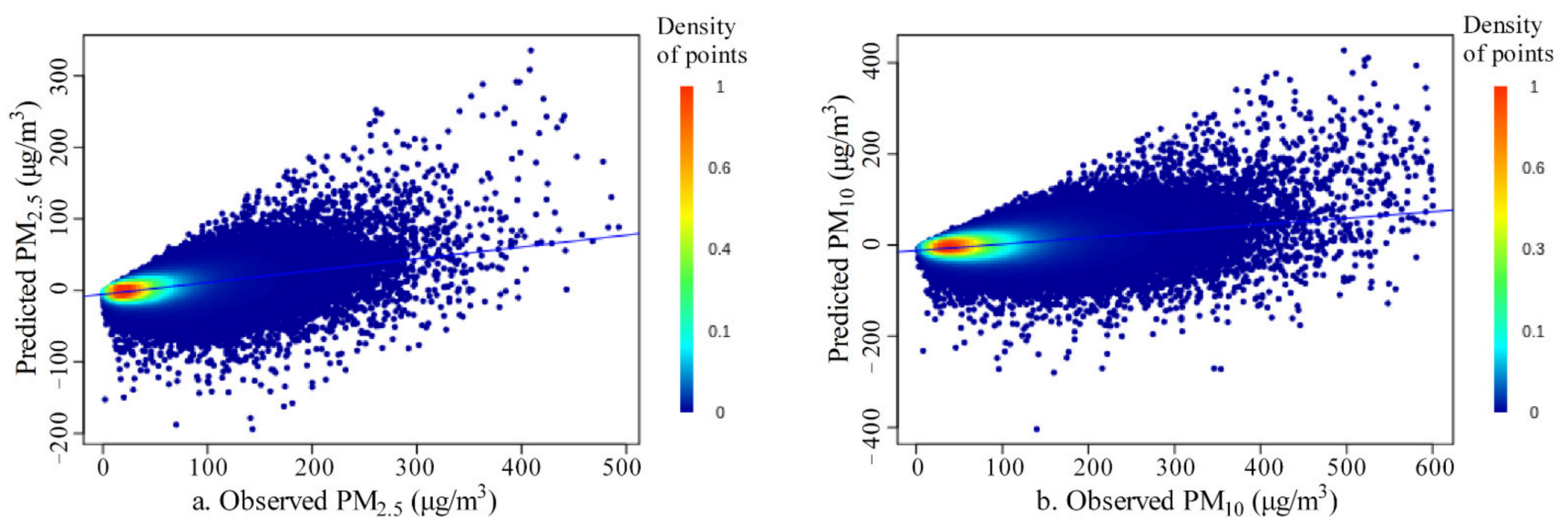

Figure 8. Scatter plots between observed values and residuals in the site-based independent testing ((a) for $\mathrm{PM}_{2.5} ;(\mathbf{b})$ for $\left.\mathrm{PM}_{10}\right)$.

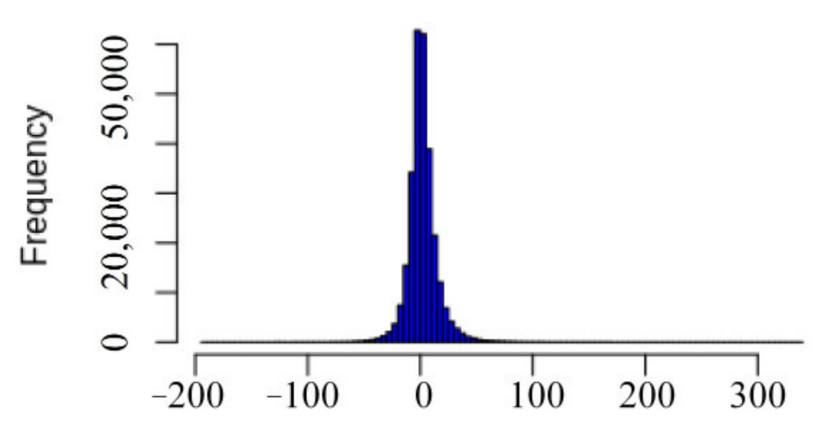

a. Residual for $\mathrm{PM}_{2.5}\left(\mu \mathrm{g} / \mathrm{m}^{3}\right)$

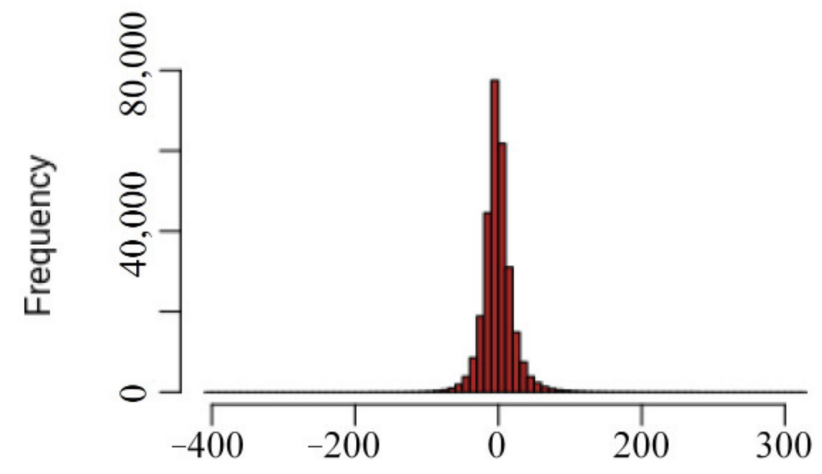

b. Residual for $\mathrm{PM}_{10}\left(\mu \mathrm{g} / \mathrm{m}^{3}\right)$

Figure 9. Histograms of the residuals in the site-based independent testing ((a) for $\mathrm{PM}_{2.5} ;(\mathbf{b})$ for $\left.\mathrm{PM}_{10}\right)$.

In addition, without the downstream network structure of the full residual deep network (Figure 3c), the local graph convolutional network only had a low performance (independent testing $\mathrm{R}^{2}$ : 0.65 for $\mathrm{PM}_{2.5}$ and $\mathrm{PM}_{10}$; RMSE: $20.98 \mu \mathrm{g} / \mathrm{m}^{3}$ for $\mathrm{PM}_{2.5}$ and $33.78 \mu \mathrm{g} / \mathrm{m}^{3}$ for $\mathrm{PM}_{10}$ ). The downstream full residual deep network improved the per- 
formance by about $29 \%$ in testing $\mathrm{R}^{2}$ and about $26-28 \%$ in site-based independent testing $\mathrm{R}^{2}$. This showed that the downstream full residual deep network considerably reduced over-smoothing in the graph convolutional network. Without geographic graph convolutions, the full residual deep network just had a low performance (independent testing $\mathrm{R}^{2}$ : $0.71-0.72$ ). The addition of GCs improved the performance by about $4-5 \%$ in testing $\mathrm{R}^{2}$ and about $15 \%$ in site-based independent testing $\mathrm{R}^{2}$. The results showed that geographic graph convolutions made a considerable contribution to the reduction in over-fitting and the improvement in generalization for the trained model. Statistics of the performance measures of the site-based independent test showed significant difference between regions (Supplementary Table S2). In particulate, compared with the other regions, Northwest China had fewer monitoring sites with complex terrain, and lower $\mathrm{R}^{2}$ and higher RMSE.

\subsection{Findings}

\subsubsection{Surfaces of Predicted $\mathrm{PM}_{2.5}$ and $\mathrm{PM}_{10}$ Concentration for Mainland China}

Using the trained model, the daily surfaces of the predicted $\mathrm{PM}_{2.5}$ and $\mathrm{PM}_{10}$ concentrations in mainland China from 2015 to 2018 were obtained. Figure 10 shows the predicted surfaces of $\mathrm{PM}_{2.5}, \mathrm{PM}_{10}$ and the ratio of $\mathrm{PM}_{2.5}$ to $\mathrm{PM}_{10}$ for four typical seasonal and yearly dates: 15 April 2015 for spring, 15 July 2016 for summer, 15 October 2017 for fall and 15 December 2018 for winter.

On the spring day of 15 April 2015, the northern part of mainland China experienced the largest sandstorm since 2002 [101]. Therefore, the $\mathrm{PM}_{10}$ concentration on this day was very high as shown in the predicted surface (Figure 10a,b). Compared with $\mathrm{PM}_{10}$, the concentration of $\mathrm{PM}_{2.5}$ on this day was not so high, and their high values were limited to local regions of North China, Northeast China and Northwest China. Although $\mathrm{PM}_{2.5}$ is a subset of $\mathrm{PM}_{10}$ particles, sand dust was one of the primary emission sources of $\mathrm{PM}_{10}$ in this sandstorm day, and the emission sources of $\mathrm{PM}_{2.5}$ mainly included combustion of gasoline, oil, diesel fuel and wood burning [102], etc. The surface of ratio of $\mathrm{PM}_{2.5}$ to $\mathrm{PM}_{10}$ (Figure 10c) showed low values in most locations, indicating that there was a significant difference between the two on this sandstorm day.

Different from the spring day of 2015, the summer day of 15 July 2016 (Figure 10d-f) had the lowest $\mathrm{PM}_{2.5}$ and $\mathrm{PM}_{10}$ concentration while the Taklimakan desert and its surrounding areas had higher concentrations of PM than other regions. In addition, the PM surfaces on the fall day of 15 October 2017 had low concentration (Figure 10g-i). The winter day of 15 December 2018 (Figure 10j-1) had the highest $\mathrm{PM}_{2.5}$ concentration, mostly located in Central and North China, and the local area of Urumqi. This winter day also had higher $\mathrm{PM}$ concentration than summer and autumn. The ratio of $\mathrm{PM}_{2.5}$ to $\mathrm{PM}_{10}$ in autumn and winter was higher than that in other seasons, indicating that many components of $\mathrm{PM}_{10}$ in these two seasons were composed of $\mathrm{PM}_{2.5}$ components.

\subsubsection{Seasonal and Yearly Variation of the Predicted Surfaces}

The daily and seasonal averages of predicted $\mathrm{PM}_{2.5}$ and $\mathrm{PM}_{10}$ surfaces were summarized for mainland China (Figure 11 for mean and median) and for seven geographic regions within it (Figures 12 and 13). Due to the influence of extreme high values, the seasonal trend of the mean was higher than that of the median; compared with the mean, the median was more robust to the extreme high values and presented a more stable seasonal trend. In addition, $\mathrm{PM}_{10}$ showed much higher standard deviation than $\mathrm{PM}_{2.5}$ (Supplementary Figure $\mathrm{S} 2$ ). $\mathrm{PM}_{2.5}$ and $\mathrm{PM}_{10}$ showed an overall downward trend year by year, and the concentration in winter was higher than that in summer. From 2015 to 2018, the annual average concentration decreased by about $15.6 \%$ for $\mathrm{PM}_{2.5}$ and by $8.9 \%$ for $\mathrm{PM}_{10}$. The ratio of $\mathrm{PM}_{2.5}$ to $\mathrm{PM}_{10}$ decreased by about $5.4 \%$, indicating that the decrease in $\mathrm{PM}_{2.5}$ contributed more to the air pollution caused by particulate matters. The results were consistent with the focus of the "declare war on pollution" policy of the government of China $[103,104]$, which was to reduce $\mathrm{PM}_{2.5}$ concentration. 


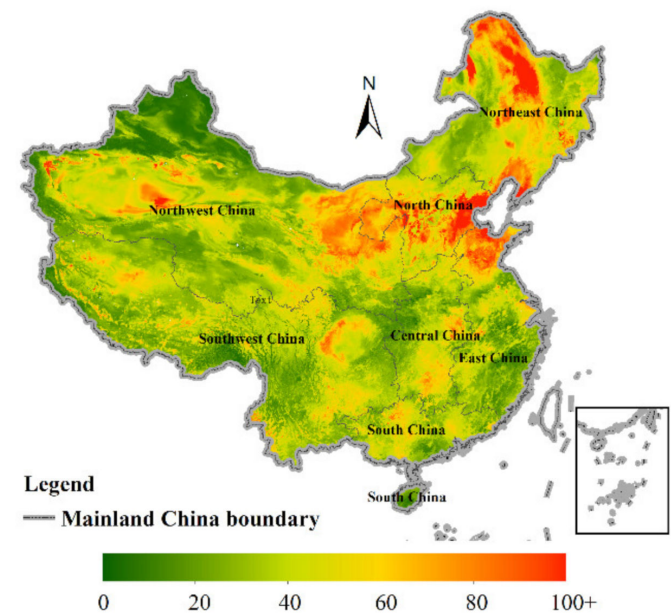

(a) Predicted PM2.5 surface in a spring day

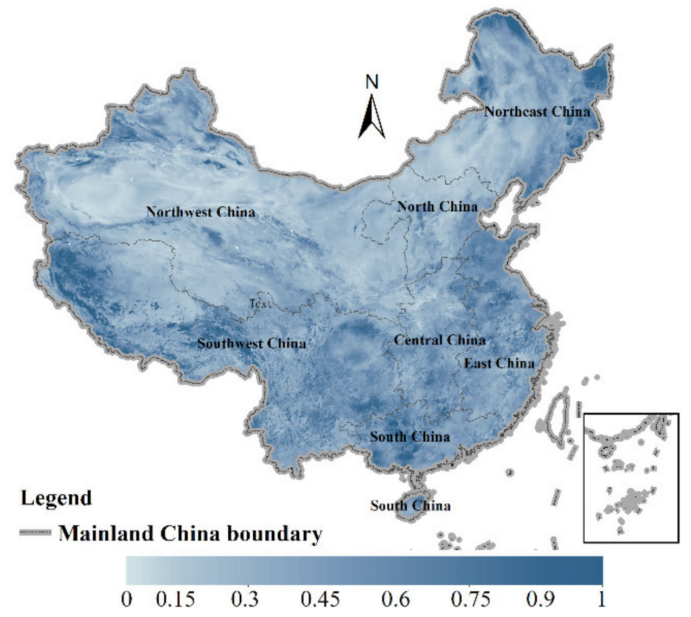

(c) Ratio of predicted $\mathrm{PM}_{2.5}$ to predicted $\mathrm{PM}_{10}$ in a spring day

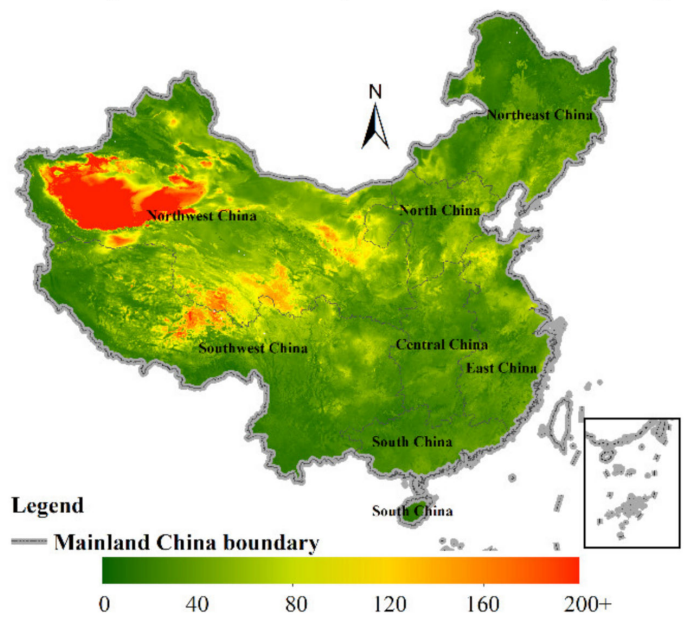

(e) Predicted PM10 surface in a summer day

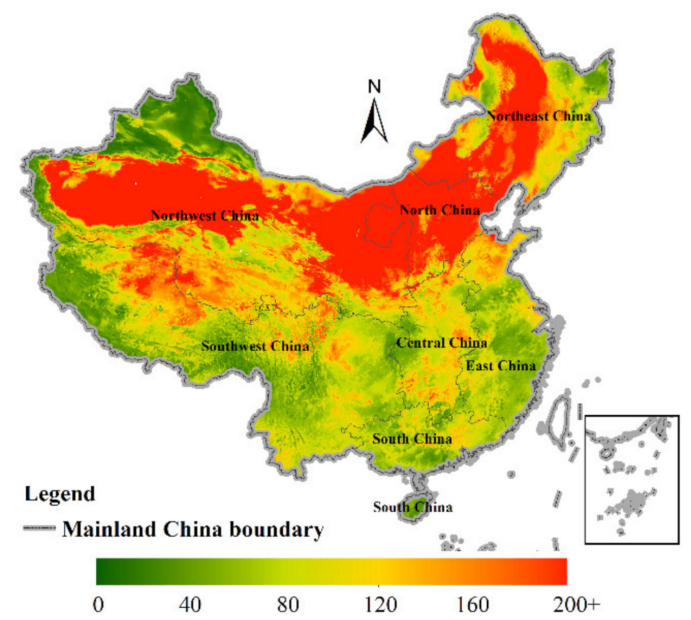

(b) Predicted PM10 surface in a spring day

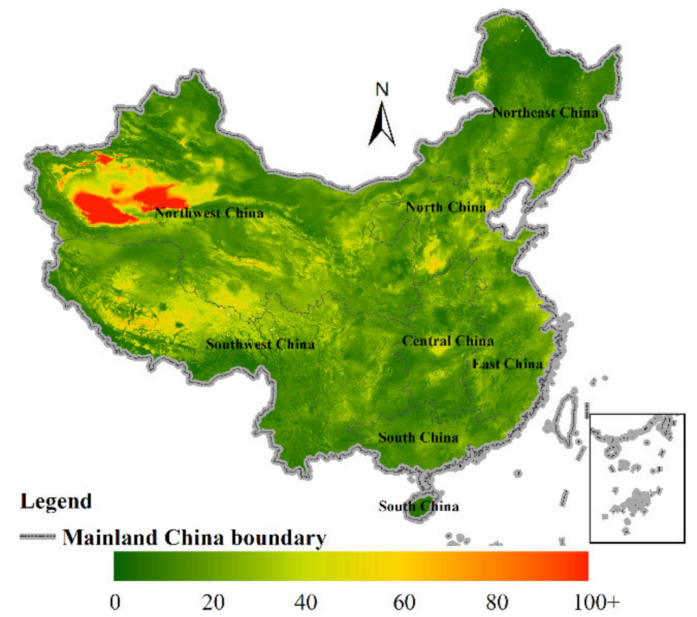

(d) Predicted PM2.5 surface in a summer day

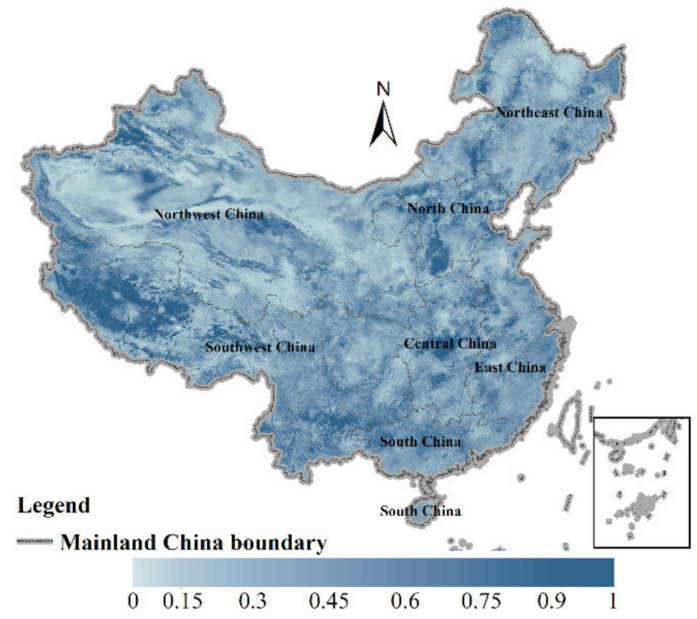

(f) Ratio of predicted $\mathrm{PM}_{2.5}$ to predicted $\mathrm{PM}_{10}$ in a summer day

Figure 10. Cont. 


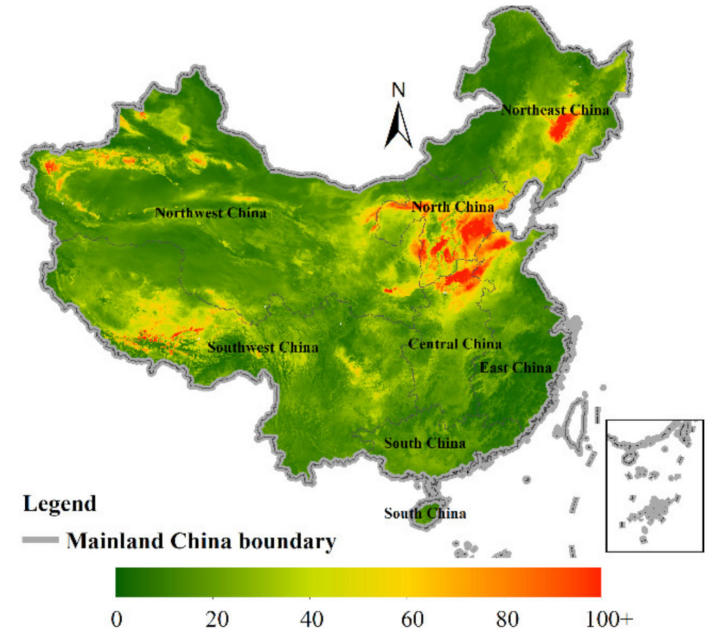

(g) Predicted PM2.5 surface in a fall day

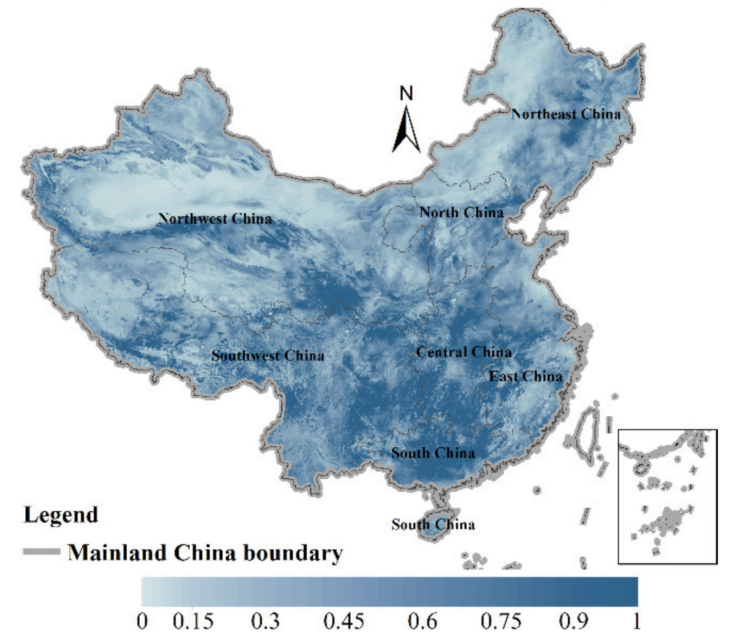

(i) Ratio of predicted $\mathrm{PM}_{2.5}$ to predicted $\mathrm{PM}_{10}$ in a fall day

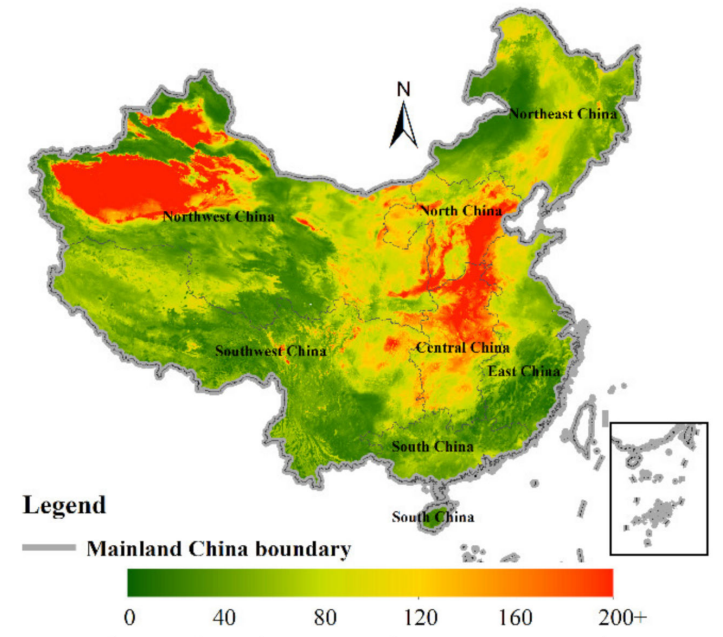

(k) Predicted $\mathrm{PM}_{10}$ surface in a winter day

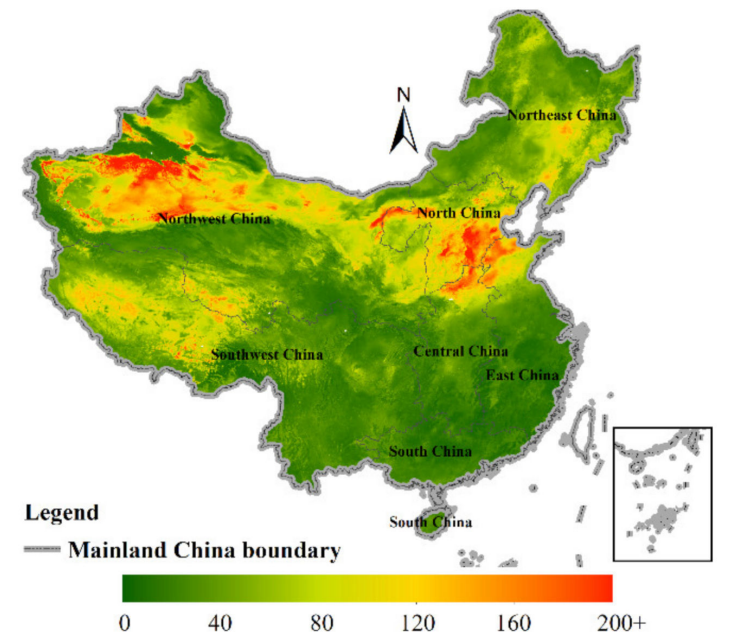

(h) Predicted PM10 surface in a fall day

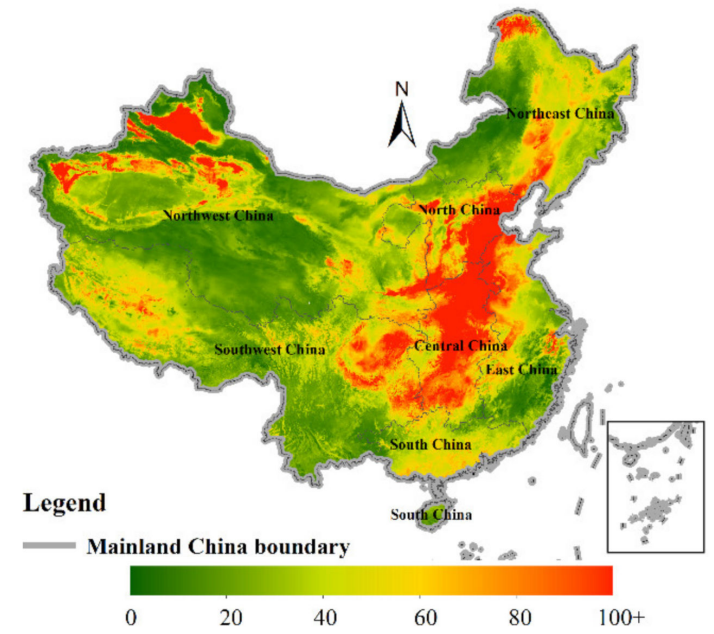

(j) Predicted PM2.5 surface in a winter day

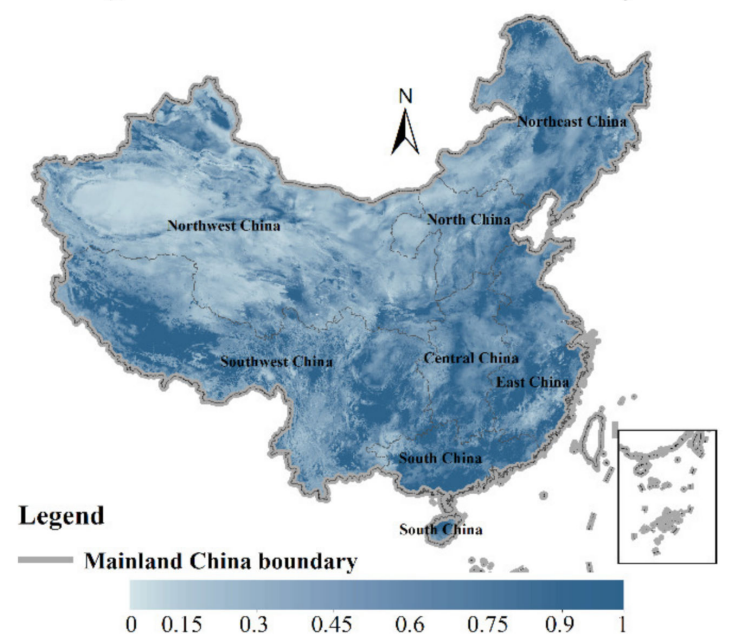

(1) Ratio of predicted $\mathrm{PM}_{2.5}$ to predicted $\mathrm{PM}_{10}$ in a winter day

Figure 10. Surfaces of predicted $\mathrm{PM}_{2.5}$ and $\mathrm{PM}_{10}$ (unit: $\mu \mathrm{g} / \mathrm{m}^{3}$ ) and their ratio of $\mathrm{PM}_{2.5}$ to $\mathrm{PM}_{10}$ for four typical seasonal days ((a-c): a spring day of 15 April 2015; (d-f): a summer day of 15 July 2016; (g-i): a fall day of 15 October 2017; (j-1) for a winter day of 15 December 2018) in mainland China. 


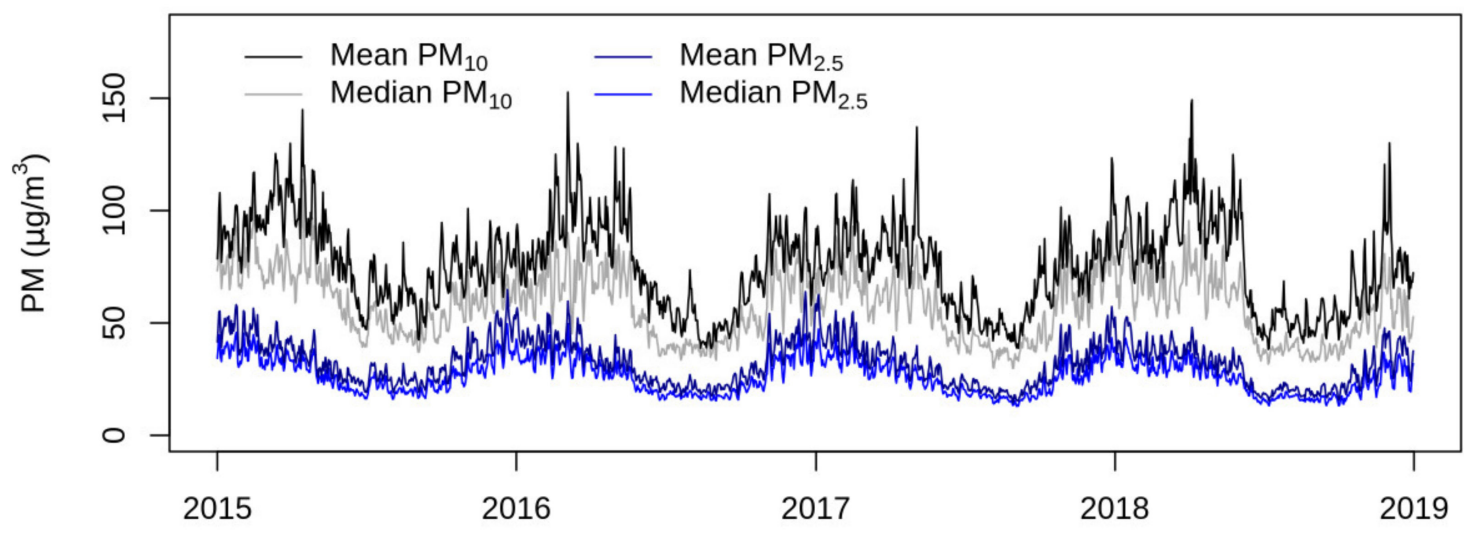

a. Date

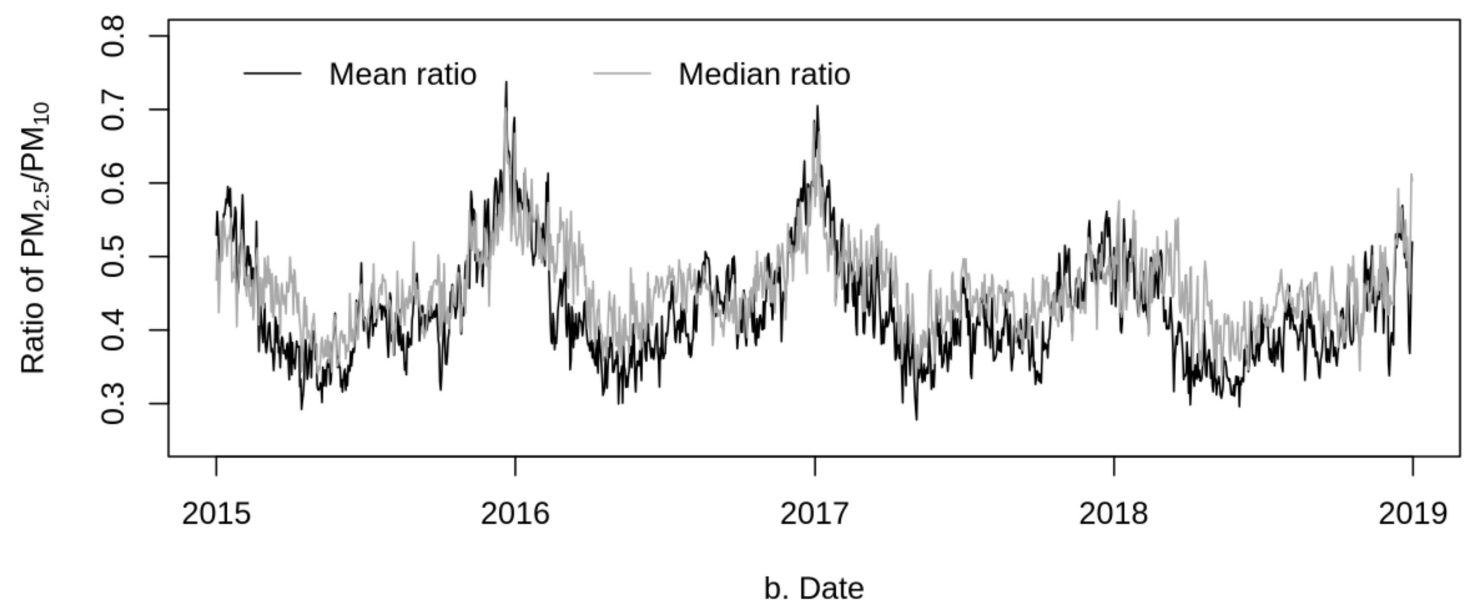

Figure 11. Time series plots of the means of predicted $\mathrm{PM}_{2.5}$ and $\mathrm{PM}_{10}$ concentrations (a) and their ratio (b) across mainland China.
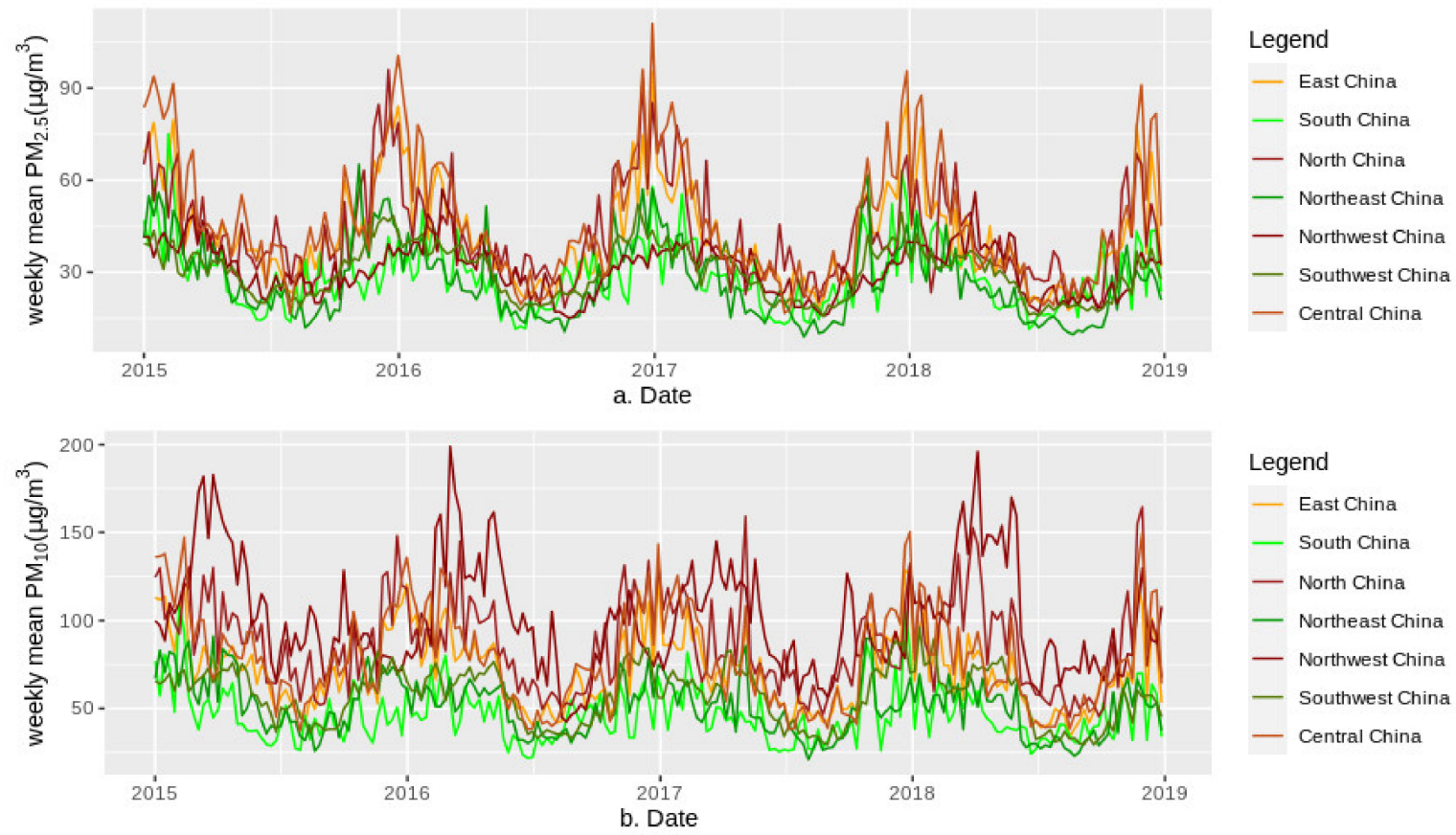

Figure 12. Weekly means of predicted $\mathrm{PM}_{2.5}$ (a) and $\mathrm{PM}_{10}$ (b) concentrations from 2015 to 2018 for seven geographical regions in mainland China. 

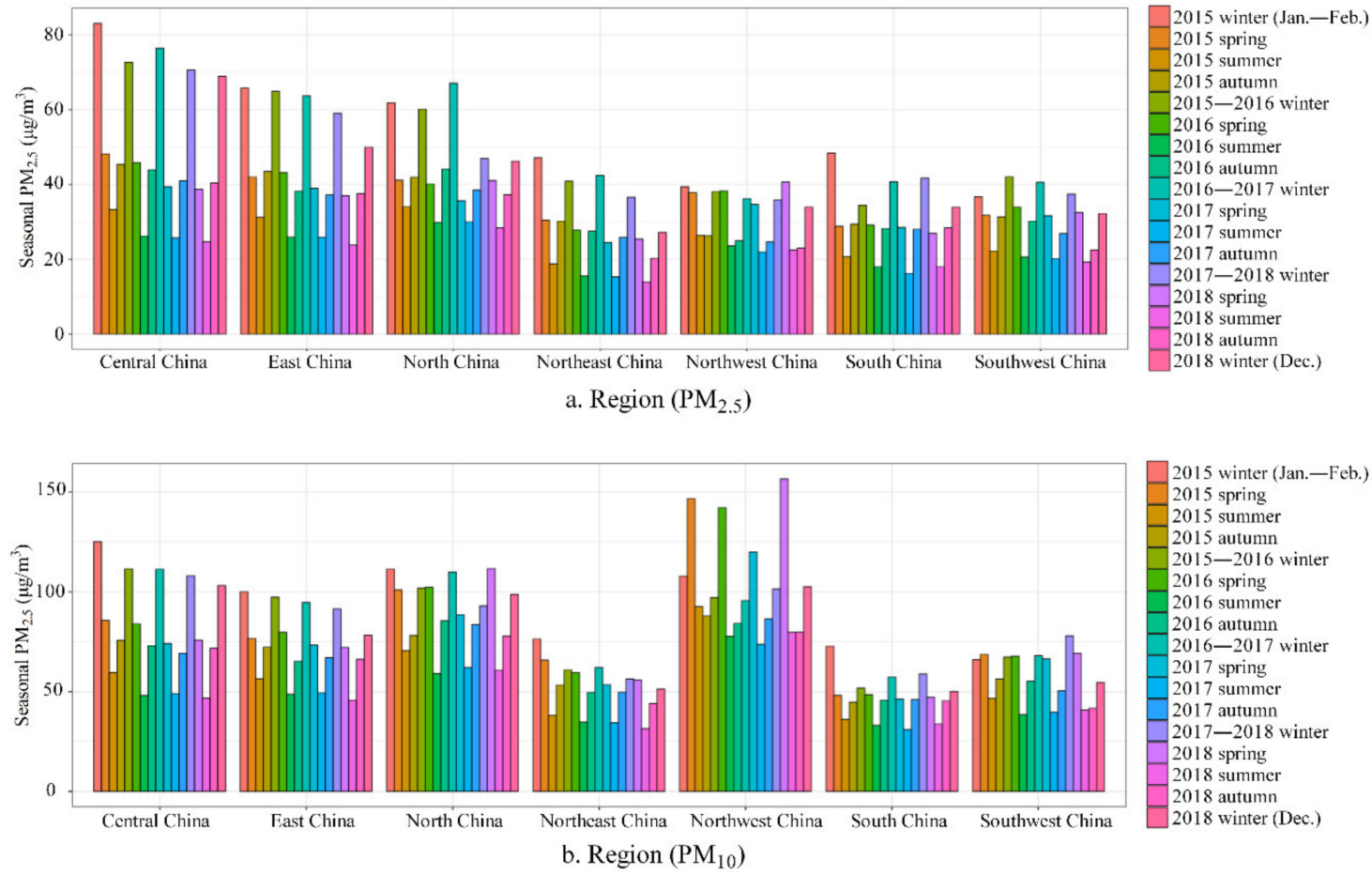

2015 winter (Jan.-Feb.)

Figure 13. Seasonal means of predicted $\mathrm{PM}_{2.5}(\mathbf{a})$ and $\mathrm{PM}_{10}$ (b) concentrations from 2015 to 2018 for seven geographical regions in mainland China.

The pollution level of $\mathrm{PM}_{2.5}$ was highest in central China, followed by eastern and northern China, as shown by seasonal changes (Figures 12 and 13). The pollution level of $\mathrm{PM}_{10}$ was highest in northwestern China, followed by northern and central China. Southern and southwestern China had the lowest levels of $\mathrm{PM}_{2.5}$ and $\mathrm{PM}_{10}$. Compared with the central, eastern and northern regions of mainland China, although the $\mathrm{PM}_{2.5}$ pollution level in northwestern China was lower, its pollution level of $\mathrm{PM}_{10}$ was the highest due to the impact of sand dust from the Taklimakan Desert, which was one of the main components of $\mathrm{PM}_{10}$ in this area. The emission sources of $\mathrm{PM}_{2.5}$ contained the combustion of gasoline, oil, diesel and wood burning, etc., in the developed regions such as central, eastern and northern China, leading to higher levels of $\mathrm{PM}_{2.5}$ in these regions compared to the other, less-developed regions. In addition, seasonal statistics (Figure 13) showed that compared with other regions with low $\mathrm{PM}_{2.5}$, the $\mathrm{PM}_{2.5}$ decline in central, eastern, northern and northeastern China was more pronounced, and the $\mathrm{PM}_{10}$ decline in central, eastern and northwestern China was more pronounced. Due to the impact of sandstorms from Mongolia, the decrease in $\mathrm{PM}_{10}$ in northern China was relatively small compared to that in $\mathrm{PM}_{2.5}$.

\subsubsection{Local Variation in the Predicted Surfaces}

Figure 14 shows the enlarged grid surfaces of predicted $\mathrm{PM}_{2.5}$ and $\mathrm{PM}_{10}$ for four typical seasonal days and four representative regions: a spring day for the Jingjintang metropolitan area $(\mathrm{a}, \mathrm{b})$, a summer day for the surrounding area of Urumqi $(\mathrm{c}, \mathrm{d})$, a fall day for the Pearl River Delta $(\mathrm{e}, \mathrm{f})$ and a winter day for the Yangtze River Delta $(\mathrm{g}, \mathrm{h})$. 


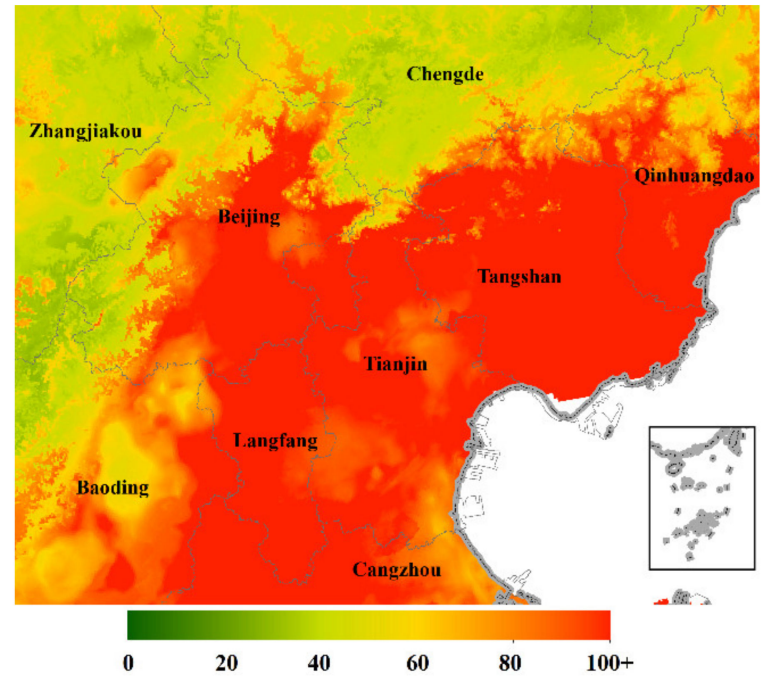

(a) $\mathrm{PM}_{2.5}$ for a spring day (15 April 2015) in Jingintang

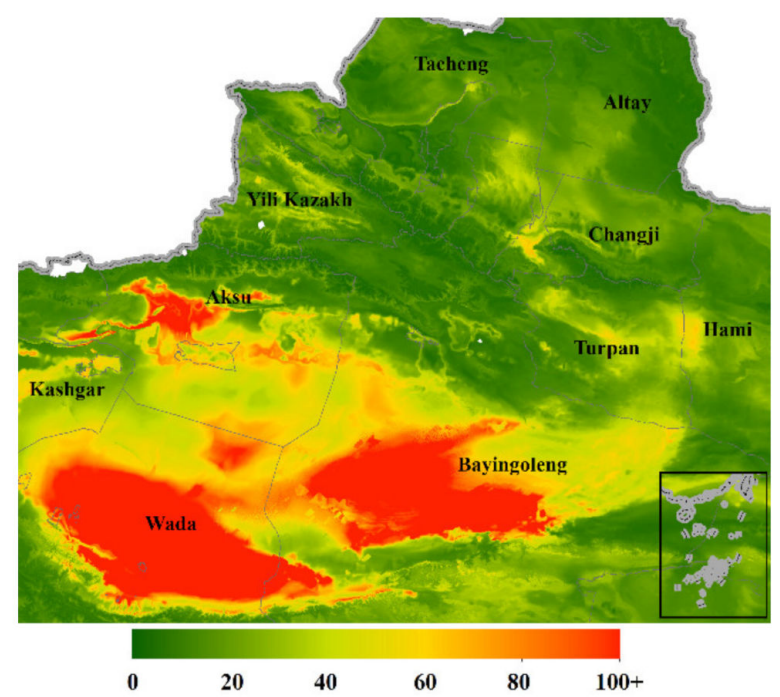

(c) PM2.5 for a summer day (15 July 2016) in the Urumqi region

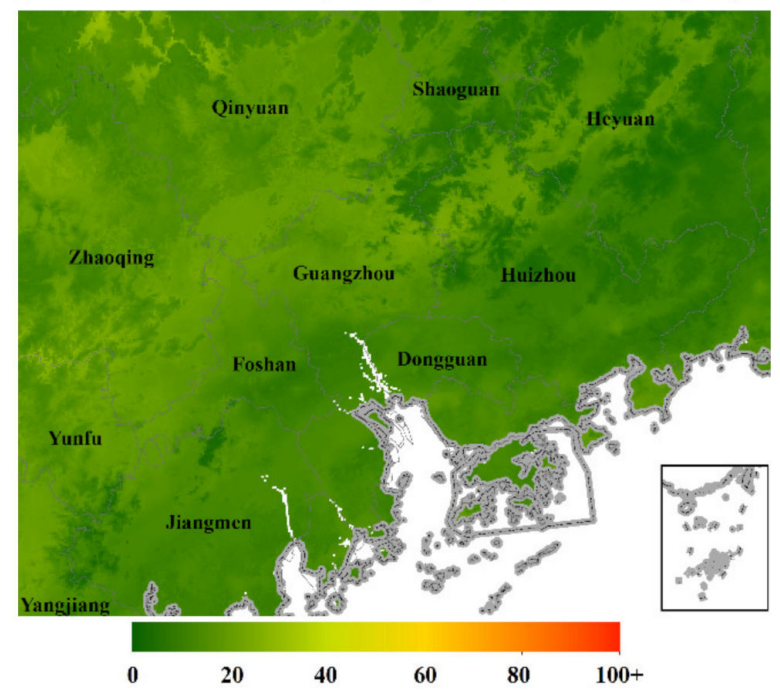

(e) PM2.5 for a fall day (15 October 2017) in Pearl River Delta

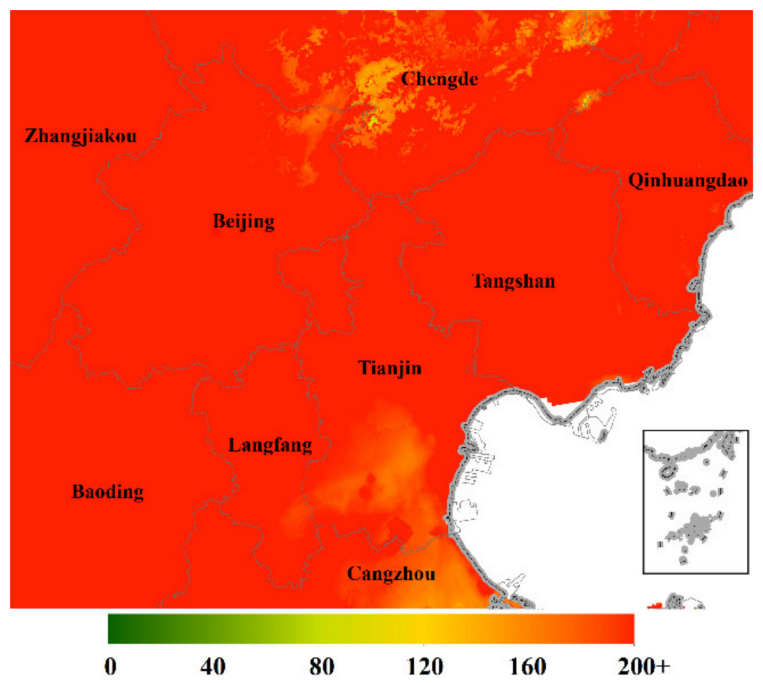

(b) PM10 for a spring day (15 April 2015) in Jingjintang

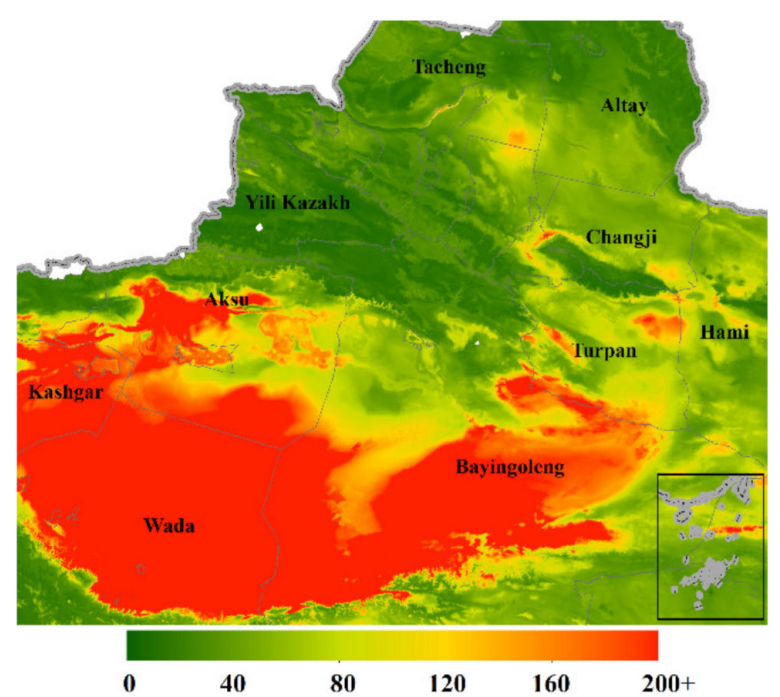

(d) $\mathrm{PM}_{10}$ for a summer day (15 July 2016) in the Urumqi region

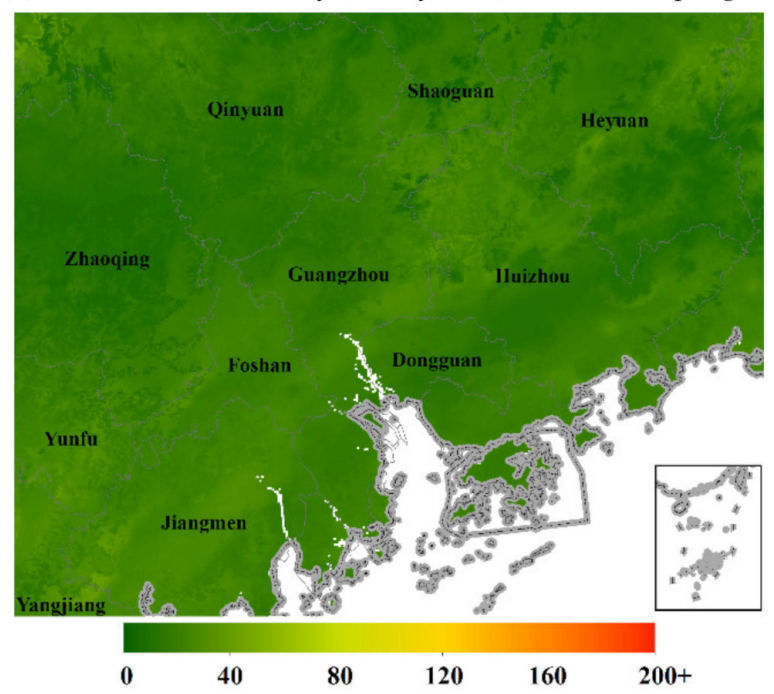

(f) PM10 for a fall day (15 October 2017) in Pearl River Delta

Figure 14. Cont. 


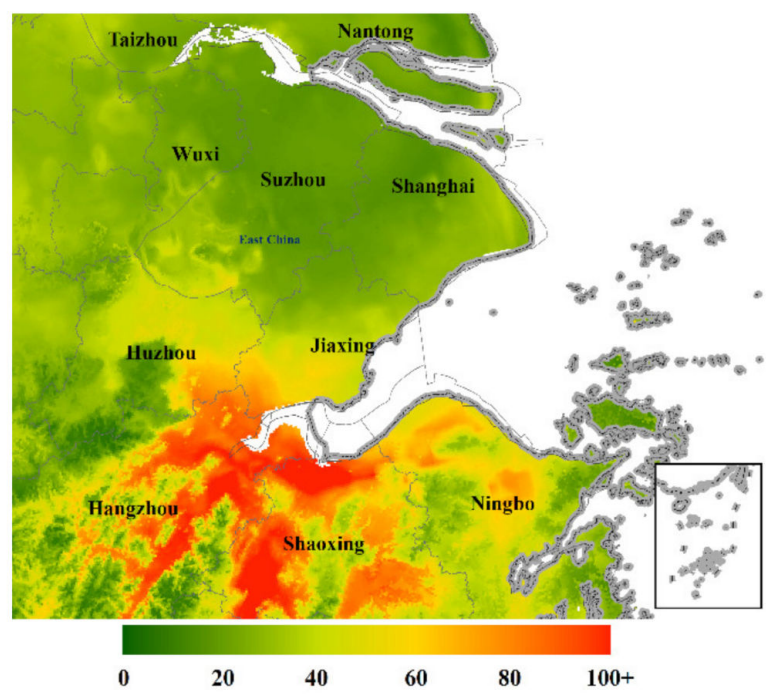

(g) PM2.5 for a winter day (15 December 2018) in Yangtze River Delta

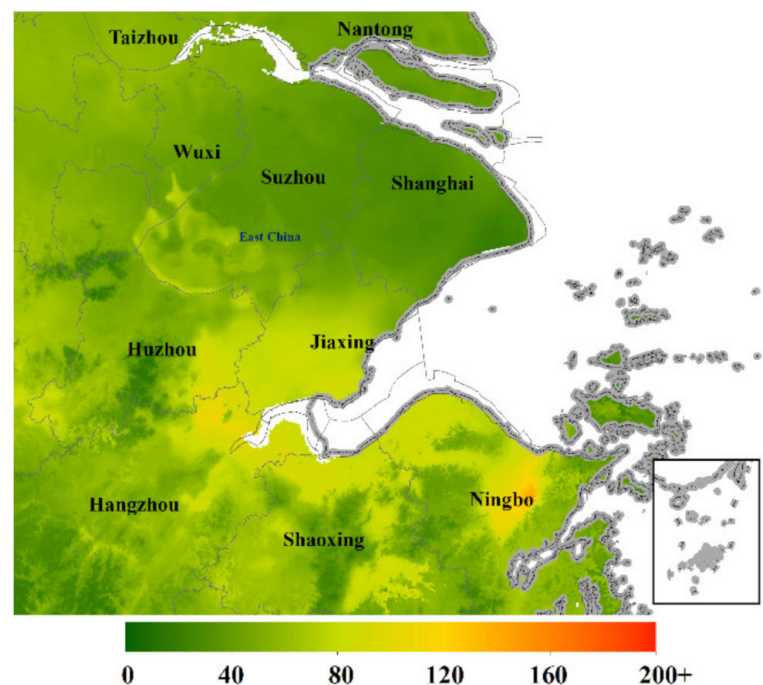

(h) PM10 for a winter day (15 December 2018) in Yangtze River Delta

Figure 14. Predicted surfaces of $\mathrm{PM}_{2.5}$ and $\mathrm{PM}_{10}$ for four typical seasonal days in four typical regions ((a,b) for the Jinjintang metropolitan area; (c,d) for the Urumqi city and its surroundings; (e,f) for Pearl River Delta; (g,h) for Yangtze River Delta).

These enlarged $1 \times 1 \mathrm{~km}^{2}$ daily surfaces of predicted pollutants clearly showed spatial distribution of $\mathrm{PM}_{2.5}$ and $\mathrm{PM}_{10}$ concentrations and significant difference between the two. For the Jingjintang region, the $\mathrm{PM}_{10}$ level in the whole area was high but the $\mathrm{PM}_{2.5}$ pollution in the northwest area was low in the sandstorm day of 2015; the desert area of Xinjiang had a higher pollution level of PM than the other regions in the summer day of 2016; the Pearl River Delta had less PM pollution than other regions in the fall day of 2017; the Yangtze River Delta had more $\mathrm{PM}_{2.5}$ pollution than $\mathrm{PM}_{10}$ in the winter of 2018.

\section{Discussion}

This paper proposes a powerful deep learning method of a geographic graph hybrid network to model the neighborhood feature to improve the generalization and extrapolation accuracy of $\mathrm{PM}_{2.5}$ and $\mathrm{PM}_{10}$. Using Tobler's First Law of Geography and local graph convolutions, the flexible hybrid framework was constructed based on spatial or spatiotemporal distances. Through powerful semi-supervised weighted embedded learning of graph convolutions, the neighborhood feature was learned from multilevel neighbors. Compared with seven representative methods, our geographic graph hybrid method substantially improved the generalization in $\mathrm{R}^{2}$ by about $8-57 \%$ for $\mathrm{PM}_{2.5}$ and $8-78 \%$ for $\mathrm{PM}_{10}$, as shown in the site-based independent test. Compared with the transductive graph network, the proposed method modeled the spatial neighborhood feature by a local inductive network structure, and thus was more generable for new samples unseen by the trained model. Compared with the-state-of-the-art methods such as random forest, XGBoost and full residual deep network, the proposed method achieved better generalization although their training performances were pretty similar. Compared with other deep learning methods, the stable learning processes of testing and site-based testing tend to converge as the index of learning epochs increases, and the fluctuations are small, indicating that the generalization has been improved. For remote areas in the study area, such as the northwestern region, compared with the other areas, there were fewer monitoring sites with complex terrain, and the site-based test performance was slightly lower, and the proposed method still worked. As far as we know, this is one of the first studies to propose the geographic graph hybrid network to improve the generalization and extrapolation of the trained model for $\mathrm{PM}_{2.5}$ and $\mathrm{PM}_{10}$.

With the strong learning ability supported by automatic differentiation and embedded learning, the proposed geographic graph hybrid network has the ability to approximate arbitrary nonlinear functions [105]. Compared with traditional spatial interpolation meth- 
ods such as kriging and regression kriging, it better captured spatial or spatiotemporal correlation, without the need to satisfy the assumptions of second-order stationarity and spatial homogeneity $[39,106]$, therefore substantially improving the generalization by about $15-51 \%$ in $\mathrm{R}^{2}$ for $\mathrm{PM}_{2.5}$ and about $17-49 \%$ in $\mathrm{R}^{2}$ for $\mathrm{PM}_{10}$. Sensitivity analysis showed that three levels of graph convolutions with 12 nearest neighbors had an optimal solution for spatiotemporal neighborhood modeling of PM. The reduction in graph convolutions and/or the number of nearest neighbors reduced the generalization of the trained model. Although a further increase in graph convolutions can further improve the generalization ability of the trained model, this improvement is trivial for PM modeling and requires more intensive computing resources. This showed that compared with neighbors that were closer to the target geo-features, the remote neighbors beyond a certain range of spatial or spatiotemporal distance had limited impact on spatial or spatiotemporal neighborhood modeling.

As the results showed, although the full residual deep network had a performance similar to the proposed geographic graph method, it performed poorer than the proposed method in regular testing and site-based independent testing. In addition, there were considerable differences $(\geq 10 \%)$ in the performance between the independent test and test ( $\mathrm{R}^{2}$ increased by about $4-5 \%$ vs. $15 \%$; RMSE decreased by about $6-10 \%$ vs. $18-20 \%$ ). This showed that the site-based independent test measured the generalization and extrapolation capability of the trained model better than the regular validation test. Sensitivity analysis also showed that the geographic graph model performed better than the nongeographic model in which all the features were used to derive the nearest neighbors and their distances. This showed that for geo-features such as $\mathrm{PM}_{2.5}$ and $\mathrm{PM}_{10}$ with strong spatial or spatiotemporal correlation, it was appropriate to use Tobler's First Law of Geography to construct a geographic graph hybrid network, and its generalization was better than general graph networks.

Compared with decision tree-based learners such as random forest and XGBoost, the proposed geographic graph method did not require discretization of input covariates [55], and maintained a full range of values of the input data, thereby avoiding information loss and bias caused by discretization. In addition, tree-based learners lacked the neighborhood modeling by graph convolution. Although the performance of random forest in training was pretty similar to the proposed method, its generalization was worse compared with the proposed method, as shown in the site-based independent test.

Compared with the pure graph network, the connection with the full residual deep layers is crucial to reduce over-smoothing in graph neighborhood modeling. The residual connections with the output of the geographic graph convolutions can make the error information directly and effectively back-propagate to the graph convolutions to optimize the parameters of the trained model. The hybrid method also makes up for the shortcomings of the lack of spatial or spatiotemporal neighborhood feature in the full residual deep network. In addition, the introduction of geographic graph convolutions makes it possible to extract important spatial neighborhood features from the nearest unlabeled samples in a semi-supervised manner. This is especially useful when a large amount of remotely sensed or simulated data (e.g., land-use, AOD, reanalysis and geographic environment) are available but only limited measured or labeled data (e.g., $\mathrm{PM}_{2.5}$ and $\mathrm{PM}_{10}$ measurement data) are available.

For PM modeling, the physical relationship $\left(\mathrm{PM}_{2.5} \leq \mathrm{PM}_{10}\right)$ between $\mathrm{PM}_{2.5}$ and $\mathrm{PM}_{10}$ was encoded in the loss through ReLU activation and RSE. Compared with a model with a single output, a model with two or more output variables (such as $\mathrm{PM}_{2.5}$ and $\mathrm{PM}_{10}$ concentrations) has the advantage that the parameters in the geographic graph model can be shared and the $\mathrm{PM}_{2.5}-\mathrm{PM}_{10}$ relationship can be embedded in the model. Sharing network parameters between different outputs also helps to reduce overfitting and improve generalization ability $[107,108]$. In particulate, the trained model can maintain a physically reasonable relationship between the output variables, which is important for the generalization and extrapolation of the trained model. Taking into account the significant 
differences in the emission sources and components of $\mathrm{PM}_{2.5}$ and $\mathrm{PM}_{10}$, the concentration grid surfaces predicted by the trained model presented significant differences in spatial and seasonal changes between the two, which were consistent with observational data and mechanical knowledge [109]. Sensitivity analysis showed that a model with a single output $\left(\mathrm{PM}_{2.5}\right.$ or $\mathrm{PM}_{10}$ concentration) and not restricted by the $\mathrm{PM}_{2.5}-\mathrm{PM}_{10}$ relationship generated a few outliers with predicted $\mathrm{PM}_{2.5}$ greater than predicted $\mathrm{PM}_{10}$, indicating that two or more shared outputs and the relational constraint between them made an important contribution to the correct predictions.

This study has several limitations. First, the unavailability of high-resolution meteorological data in certain regions and time periods may limit the applicability of the proposed $\mathrm{PM}_{2.5}$ and $\mathrm{PM}_{10}$ inversion method. However, based on the publicly shared measurement data of meteorological monitoring stations and coarse-resolution reanalysis data, reliable high-resolution meteorological data can be easily inversed by using existing deep learning interpolation methods $[85,86]$. In addition, the other high-resolution meteorological dataset can alternatively be used for the proposed method. For example, the Gridded Surface Meteorological (gridMET) Dataset [110] can be used to estimate $\mathrm{PM}_{2.5}$ and $\mathrm{PM}_{10}$ concentrations for contiguous U.S. Second, the proposed method only estimated the total concentrations of $\mathrm{PM}_{2.5}$ and $\mathrm{PM}_{10}$, which was limited for accurately identifying the health risks of PM pollutants. The compositions and sizes of PM are different in different countries and regions, with different toxicity and health effects [102]. Accurate estimation of the hazardous components of the PM pollutants is important for downstream assessment of their health effects, and pollution prevention and control. However, considering the lack of expensive measurement data of PM constituents and their high regional variability, the inversion of PM compositions is really challenging. Third, although a total of 20 geographic graph hybrid networks were trained to obtain average performance, the training model had no uncertainty estimation, which was one of the limitations of this study.

In terms of future prospects, an extension of this research is to adapt the proposed method to effectively predict the most hazardous constituents of PM, in a semi-supervised manner, when only limited measurement data of PM constituents are available. Thereby the health risk of PM pollutants can be more accurately identified. Another future extension is uncertainty estimation, which is important as it can be provided as useful information for downstream applications. For the proposed method, the nonparametric bootstrapping method can be used to estimate the prediction error as an uncertainty measure. This method performs similarly to the parametric one, but it is widely used for various applications, including non-normal noise and nonlinear data, such as PM estimation.

\section{Conclusions}

This study presents a novel deep geometric learning method that combines a geographic graph network and a full residual deep network for robust spatial or spatiotemporal prediction of $\mathrm{PM}_{2.5}$ and $\mathrm{PM}_{10}$. According to Tobler's First Law of Geography and local graph convolutions, compared with nongeographic models, the geographic graph hybrid network is constructed to be flexible, inducive and generalizable. The spatial or spatiotemporal neighborhood feature is encoded by local multilevel graph convolutions and extracted from the surrounding nearest sensed data from satellite and/or UAVs. Limited measured or labeled data of the dependent (target) variable(s) are then used to drive adaptive learning of the geographic graph hybrid model. The physical $\mathrm{PM}_{2.5}-\mathrm{PM}_{10}$ relationship is also encoded in the loss function to decrease over-fitting and intractable bias in the prediction. In the national forecast of $\mathrm{PM}_{2.5}$ and $\mathrm{PM}_{10}$ in mainland China, compared with seven representative methods, the presented method considerably improves $\mathrm{R}^{2}$ by $8-87 \%$ and reduces RMSE by $14-48 \%$ in site-based independent tests. With high $\mathrm{R}^{2}$ of $0.82-0.83$ in the independent test, the geographic graph hybrid method created the inversion of $\mathrm{PM}_{2.5}$ and $\mathrm{PM}_{10}$ at the high spatial $\left(1 \times 1 \mathrm{~km}^{2}\right)$ and temporal resolution (daily), which was consistent with observed spatiotemporal trends and patterns. This study has important 
implications for high-accuracy and high-resolution robust inversions of geo-features with strong spatial or spatiotemporal correlation such as air pollutants of $\mathrm{PM}_{2.5}$ and $\mathrm{PM}_{10}$.

Supplementary Materials: The following are available online at https://www.mdpi.com/article/ 10.3390/rs13214341/s1: Figure S1: Bar plots of SHAP values of the trained model (a for $\mathrm{PM}_{2.5}$ and $\mathrm{b}$ for $\mathrm{PM}_{10}$ ); Figure S2: Time series plots of the standard deviations of predicted $\mathrm{PM}_{2.5}$ and $\mathrm{PM}_{10}$ concentrations across mainland China; Table S1: Statistics of meteorological factors for the PM monitoring sites; Table S2: Statistics of the performance metrics of the site-based independent test in mainland China and its geographic regions.

Funding: This work was supported in part by the National Natural Science Foundation of China under Grant 42071369 and 41871351, and in part by the Strategic Priority Research Program of the Chinese Academy of Sciences under Grant XDA19040501.

Institutional Review Board Statement: Not applicable.

Informed Consent Statement: Not applicable.

Data Availability Statement: The sample data for mainland China can be obtained from https:// github.com/lspatial/geographnetdata (accessed on 1 October 2021). The Python library of Geographic Graph Hybrid Network is publicly available at https:/ / pypi.org/project/geographnet (accessed on 1 October 2021) or https://github.com/lspatial/geographnet (accessed on 1 October 2021).

Acknowledgments: The support of NVIDIA Corporation through the donation of the Titan Xp GPUs. The author acknowledges the contribution of Jiajie $\mathrm{Wu}$ for data processing.

Conflicts of Interest: The authors declare no conflict of interest.

\section{Appendix A}

Table A1. MERRA2 and MERRA2-GMI covariates for PM modeling.

\begin{tabular}{|c|c|c|c|}
\hline Class & Variable & Unit & Description and Source \\
\hline PBLH & Planetary boundary layer height (PBLH) & $\mathrm{m}$ & From NASA GMI. \\
\hline \multirow{4}{*}{ MERRA2-GMI } & $\begin{array}{l}\text { Carbon monoxide } \\
\text { Dust mass mixing ratio } \mathrm{PM}_{2.5} \\
\text { Nitrate mass mixing ratio } \\
\text { Nitrogen dioxide } \\
\text { Ozone } \\
\text { Organic carbon mass mixing ratio } \\
\text { Total reconstructed } \mathrm{PM}_{2.5} \\
\text { Sea salt mass mixing ratio } \mathrm{PM}_{2.5}\end{array}$ & $\begin{array}{c}\mathrm{mol} \mathrm{mol}^{-1} \\
\mathrm{~kg} \mathrm{~kg}^{-1} \\
\mathrm{~kg} / \mathrm{kg}^{-1} \\
\mathrm{~mol} \mathrm{~mol}^{-1} \\
\mathrm{~mol} \mathrm{~mol}^{-1} \\
\mathrm{~kg} \mathrm{~kg}^{-1} \\
\mathrm{~kg} \mathrm{~m}^{-3} \\
\mathrm{~kg} \mathrm{~kg}^{-1}\end{array}$ & $\begin{array}{l}\text { Bottom layer diagnostics ( } 50-60 \mathrm{~m} \text { above the } \\
\text { ground): hourly values for a variety of } \\
\text { surface-level values, including } \mathrm{PM}, \mathrm{PM}_{2.5}, \mathrm{NO} \text { and } \\
\mathrm{NO}_{2} \text {. These will likely provide the most valuable } \\
\text { model inputs. }\end{array}$ \\
\hline & $\begin{array}{l}\text { Black carbon surface mass concentration } \\
\text { DMS surface mass concentration } \\
\text { Dust surface mass concentration- } \mathrm{PM}_{2.5} \\
\text { Nitric acid surface mass concentration } \\
\text { Nitrate surface mass concentration } \\
\text { Organic carbon surface mass concentration } \\
\text { Total reconstructed } \mathrm{PM}_{2.5} \\
\mathrm{SO}_{2} \text { surface mass concentration } \\
\text { Sea salt surface mass concentration } \mathrm{PM}_{2.5} \\
\text { Total aerosol extinction AOT [550 nm] }\end{array}$ & $\begin{array}{l}\mathrm{kg} \mathrm{m}^{-3} \\
\mathrm{~kg} \mathrm{~m}^{-3} \\
\mathrm{~kg} \mathrm{~m}^{-3} \\
\mathrm{~kg} \mathrm{~m}^{-3} \\
\mathrm{~kg} \mathrm{~m}^{-3} \\
\mathrm{~kg} \mathrm{~m}^{-3} \\
\mathrm{~kg} \mathrm{~m}^{-3} \\
\mathrm{~kg} \mathrm{~m}^{-3} \\
\mathrm{~kg} \mathrm{~m}^{-3} \\
\quad-\end{array}$ & $\begin{array}{l}\text { Aerosol diagnostics: total aerosol extinction on an } \\
\text { hourly basis, which may be used for model input } \\
\text { (and estimates of surface mass concentrations for } \\
\text { black carbon, dust, etc.). }\end{array}$ \\
\hline & $\begin{array}{l}\text { Sulfur dioxide local } \\
\text { Nitrogen dioxide local }\end{array}$ & $\begin{array}{l}\mathrm{mol} \mathrm{mol}^{-1} \\
\mathrm{~mol} \mathrm{~mol}^{-1}\end{array}$ & $\begin{array}{l}\text { Daily satellite overpass fields: instantaneous } \\
\text { measurements at } 10 \mathrm{AM} \text { and } 2 \mathrm{PM} \text { local time. }\end{array}$ \\
\hline & $\begin{array}{l}50 \mathrm{~m} \text { eastward wind; } 10 \mathrm{~m} \text { eastward wind; } \\
2 \mathrm{~m} \text { eastward wind; } 50 \mathrm{~m} \text { northward wind; } \\
10 \mathrm{~m} \text { northward wind; } 2 \mathrm{~m} \text { northward wind } \\
\text { total tropospheric ozone }\end{array}$ & $\begin{array}{l}\mathrm{m} \mathrm{s}^{-1} \\
\text { Dobsons }\end{array}$ & $\begin{array}{l}\text { Single-level diagnostics: basic meteorological } \\
\text { information such as temperature and humidity at } \\
2 \mathrm{~m} \text { and } 10 \mathrm{~m} \text {. These may be useful model inputs. }\end{array}$ \\
\hline $\begin{array}{l}\text { Derived wind } \\
\text { variables }\end{array}$ & $\begin{array}{l}\text { Stagnation of wind speed, derived from } \\
\text { wind speeds of single-level diagnostics. } \\
\text { Wind mechanical mixing, derived from } \\
\text { wind speeds of single-level diagnostics. }\end{array}$ & $\mathrm{m} / \mathrm{s}$ & $\begin{array}{l}w_{\text {stag }}=\left(\sqrt{u_{50}^{2}+v_{50}^{2}}-\sqrt{u_{10}^{2}+v_{10}^{2}}\right) \\
w_{\text {stag }}=\left(\sqrt{u_{10}^{2}+v_{10}^{2}}-\sqrt{u_{2}^{2}+v_{2}^{2}}\right)\end{array}$ \\
\hline
\end{tabular}




\section{References}

1. WHO. Health Effects of Particulate Matter: Policy Implications for Countries in Eastern Europe, Caucasus and Central Asia; WHO: Geneva, Switzerland, 2013.

2. Dawson, J.P.; Adams, P.J.; Pandis, S.N. Sensitivity of $\mathrm{PM}_{2.5}$ to climate in the Eastern US: A modeling case study. Atmos. Chem. Phys. Discuss. 2007, 7, 4295-4309. [CrossRef]

3. Hong, C.; Zhang, Q.; Zhang, Y.; Davis, S.J.; Tong, D.; Zheng, Y.; Liu, Z.; Guan, D.; He, K.; Schellnhuber, H.J. Impacts of climate change on future air quality and human health in China. Proc. Natl. Acad. Sci. USA 2019, 116, 17193-17200. [CrossRef] [PubMed]

4. IASS. Air Pollution and Climate Change. Available online: https://www.iass-potsdam.de/en/output/dossiers/air-pollutionand-climate-change (accessed on 1 March 2021).

5. Kloog, I.; Ridgway, B.; Koutrakis, P.; Coull, B.A.; Schwartz, J.D. Long- and short-term exposure to PM 2.5 and mortality. Epidemiology 2013, 24, 555-561. [CrossRef] [PubMed]

6. Yang, Y.; Ruan, Z.; Wang, X.; Yang, Y.; Mason, T.G.; Lin, H.; Tian, L. Short-term and long-term exposures to fine particulate matter constituents and health: A systematic review and meta-analysis. Environ. Pollut. 2019, 247, 874-882. [CrossRef] [PubMed]

7. Benaissa, F.; Maesano, C.N.; Alkama, R.; Annesi-Maesano, I. Short-term health impact assessment of urban PM 10 in Bejaia City (Algeria). Can. Respir. J. 2016, 2016, 1-6. [CrossRef]

8. Maciejewska, K. Short-term impact of $\mathrm{PM}_{2.5}, \mathrm{PM}_{10}$, and PMc on mortality and morbidity in the agglomeration of Warsaw, Poland. Air Qual. Atmos. Health 2020, 13, 659-672. [CrossRef]

9. Zeka, A.; Zanobetti, A.; Schwartz, J. Short term effects of particulate matter on cause specific mortality: Effects of lags and modification by city characteristics. Occup. Environ. Med. 2005, 62, 718-725. [CrossRef]

10. Hoek, G.; Krishnan, R.M.; Beelen, R.; Peters, A.; Ostro, B.; Brunekreef, B.; Kaufman, J.D. Long-term air pollution exposure and cardio- respiratory mortality: A review. Environ. Health 2013, 12, 43. [CrossRef]

11. EPA. Air Quality and Climate Change Research. Available online: https:/ / www.epa.gov/air-research/air-quality-and-climatechange-research (accessed on 2 July 2021).

12. Zhang, G.; Rui, X.; Fan, Y. Critical review of methods to estimate $\mathrm{PM}_{2.5}$ concentrations within specified research region. ISPRS Int. J. Geo-Inform. 2018, 7, 368. [CrossRef]

13. Borghi, F.; Spinazzè, A.; Campagnolo, D.; Rovelli, S.; Cattaneo, A.; Cavallo, D.M. Precision and accuracy of a direct-reading miniaturized monitor in $\mathrm{PM}_{2.5}$ exposure assessment. Sensors 2018, 18, 3089. [CrossRef]

14. NASA. MODIS Atmosphere. Available online: https:/ / modis-images.gsfc.nasa.gov/products.html (accessed on 3 September 2020).

15. NASA. MODIS Grids. Available online: https://modis-land.gsfc.nasa.gov/MODLAND_grid.html (accessed on 1 June 2021).

16. Lyapustin, A.; Martonchik, J.; Wang, Y.; Laszlo, I.; Korkin, S. Multiangle implementation of atmospheric correction (MAIAC): 1. Radiative transfer basis and look-up tables. J. Geophys. Res. Space Phys. 2011, 116. [CrossRef]

17. Lyapustin, A.; Wang, Y. MODIS Multi-Angle Implementation of Atmospheric Correction (MAIAC) Data User's Guide; NASA. 2016. Available online: https://lpdaac.usgs.gov/documents/110/MCD19_User_Guide_V6.pdf (accessed on 1 April 2019).

18. Lyapustin, A.; Wang, Y.; Laszlo, I.; Kahn, R.; Korkin, S.; Remer, L.; Levy, R.; Reid, J.S. Multiangle implementation of atmospheric correction (MAIAC): 2. Aerosol algorithm. J. Geophys. Res. Space Phys. 2011, 116. [CrossRef]

19. Lyapustin, A.; Wang, Y.; Korkin, S.; Huang, D. MODIS Collection 6 MAIAC algorithm. Atmos. Meas. Tech. 2018, 11, 5741-5765. [CrossRef]

20. Mhawish, A.; Banerjee, T.; Sorek-Hamer, M.; Lyapustin, A.; Broday, D.M.; Chatfield, R. Comparison and evaluation of MODIS Multi-angle Implementation of Atmospheric Correction (MAIAC) aerosol product over South Asia. Remote. Sens. Environ. 2019, 224, 12-28. [CrossRef]

21. Tao, M.; Wang, J.; Li, R.; Wang, L.; Wang, L.; Wang, Z.; Tao, J.; Che, H.; Chen, L. Performance of MODIS high-resolution MAIAC aerosol algorithm in China: Characterization and limitation. Atmos. Environ. 2019, 213, 159-169. [CrossRef]

22. Chiliński, M.T.; Markowicz, K.; Kubicki, M. UAS as a support for atmospheric aerosols research: Case study. Pure Appl. Geophys. PAGEOPH 2018, 175, 3325-3342. [CrossRef]

23. Mamali, D.; Marinou, E.; Sciare, J.; Pikridas, M.; Kokkalis, P.; Kottas, M.; Binietoglou, I.; Tsekeri, A.; Keleshis, C.; Engelmann, R.; et al. Vertical profiles of aerosol mass concentration derived by unmanned airborne in situ and remote sensing instruments during dust events. Atmos. Meas. Tech. 2018, 11, 2897-2910. [CrossRef]

24. Pikridas, M.; Bezantakos, S.; Močnik, G.; Keleshis, C.; Brechtel, F.; Stavroulas, I.; Demetriades, G.; Antoniou, P.; Vouterakos, P.; Argyrides, M.; et al. On-flight intercomparison of three miniature aerosol absorption sensors using unmanned aerial systems (UASs). Atmos. Meas. Tech. 2019, 12, 6425-6447. [CrossRef]

25. NASA. Modern-Era Retrospective Analysis for Research and Applications, Version 2. Available online: https://gmao.gsfc.nasa. gov/reanalysis/MERRA-2/ (accessed on 1 April 2020).

26. Nielsen, J.E.; Pawson, S.; Molod, A.; Auer, B.; da Silva, A.M.; Douglass, A.R.; Duncan, B.; Liang, Q.; Manyin, M.; Oman, L.D.; et al. Chemical mechanisms and their applications in the Goddard Earth Observing System (GEOS) earth system model. J. Adv. Model. Earth Syst. 2017, 9, 3019-3044. [CrossRef]

27. Akyurtlu, A.; Akyurtlu, J. Investitation of Fine Particulate Matter, NOx and Tropospheric Ozone Transport Around a Major Roadway; Hampton University: Hampton, VI, USA, 2013. 
28. Frontera, A.; Martin, C.; Vlachos, K.; Sgubin, G. Regional air pollution persistence links to COVID-19 infection zoning. J. Infect. 2020, 81, 318-356. [CrossRef]

29. Li, M.; Wang, L.; Liu, J.; Gao, W.; Song, T.; Sun, Y.; Li, L.; Li, X.; Wang, Y.; Liu, L.; et al. Exploring the regional pollution characteristics and meteorological formation mechanism of $\mathrm{PM}_{2.5}$ in North China during 2013-2017. Environ. Int. 2020, 134, 105283. [CrossRef]

30. Benson, P. CALINE4-A Dispersion Model for Predicting Air Pollutant Concentrations Near Roadways; California Department of Transportation: Sacramento CA, USA, 1989.

31. Bey, I.; Jacob, D.J.; Yantosca, R.; Logan, J.A.; Field, B.D.; Fiore, A.M.; Li, Q.; Liu, H.Y.; Mickley, L.J.; Schultz, M. Global modeling of tropospheric chemistry with assimilated meteorology: Model description and evaluation. J. Geophys. Res. Space Phys. 2001, 106, 23073-23095. [CrossRef]

32. Byun, D.W.; Ching, J. Science Algorithms of the EPA Models-3 Community Multiscale Air Quality (CMAQ) Modeling System; United States Environmental Protection Agency: Washington, DC, USA, 1999.

33. EPA. CMAQ v5.2 Operational Guidance Document. Available online: https://github.com/USEPA/CMAQ/blob/5.2/DOCS/ User_Manual/README.md (accessed on 2 July 2020).

34. Quennehen, B.; Raut, J.-C.; Law, K.S.; Daskalakis, N.; Ancellet, G.; Clerbaux, C.; Kim, S.-W.; Lund, M.T.; Myhre, G.; Olivié, D.J.L.; et al. Multi-model evaluation of short-lived pollutant distributions over east Asia during summer 2008. Atmos. Chem. Phys. Discuss. 2016, 16, 10765-10792. [CrossRef]

35. Appel, K.W.; Chemel, C.; Roselle, S.; Francis, X.V.; Hu, R.-M.; Sokhi, R.S.; Rao, S.; Galmarini, S. Examination of the Community Multiscale Air Quality (CMAQ) model performance over the North American and European domains. Atmos. Environ. 2012, 53, 142-155. [CrossRef]

36. Butland, B.K.; Armstrong, B.; Atkinson, R.W.; Wilkinson, P.; Heal, M.R.; Doherty, R.M.; Vieno, M. Measurement error in time-series analysis: A simulation study comparing modelled and monitored data. BMC Med. Res. Methodol. 2013, 13, 136. [CrossRef]

37. Strickland, M.J.; Gass, K.; Goldman, G.T.; Mulholland, J.A. Effects of ambient air pollution measurement error on health effect estimates in time-series studies: A simulation-based analysis. J. Expo. Sci. Environ. Epidemiol. 2015, 25, 160-166. [CrossRef]

38. Strickland, M.J.; Hao, H.; Hu, X.; Chang, H.H.; Darrow, L.A.; Liu, Y. Pediatric emergency visits and short-term changes in pm concentrations in the U.S. State of Georgia. Environ. Health Perspect. 2016, 124, 690-696. [CrossRef]

39. Cressie, N. The origins of kriging. Math. Geol. 1990, 22, 239-252. [CrossRef]

40. Gribov, A.; Krivoruchko, K. Empirical Bayesian kriging implementation and usage. Sci. Total Environ. 2020, $722,137290$. [CrossRef]

41. Goovaerts, P. Geostatistics for Natural Resources Evaluation; Oxford University Press: Oxford, UK, 1997.

42. Goovaerts, P. Ordinary cokriging revisited. Math. Geol. 1998, 30, 21-42. [CrossRef]

43. Chu, Y.; Liu, Y.; Li, X.; Liu, Z.; Lu, H.; Lu, Y.; Mao, Z.; Chen, X.; Li, N.; Ren, M.; et al. A review on predicting ground PM 2.5 concentration using satellite aerosol optical depth. Atmosphere 2016, 7, 129. [CrossRef]

44. Hoek, G.; Beelen, R.; de Hoogh, K.; Vienneau, D.; Gulliver, J.; Fischer, P. A review of land-use regression models to assess spatial variation of outdoor air pollution. Atmos. Environ. 2008, 42, 7561-7578. [CrossRef]

45. Lin, Y.; Zou, J.; Yang, W.; Li, C.-Q. A review of recent advances in research on $\mathrm{PM}_{2.5}$ in China. Int. J. Environ. Res. Public Health 2018, 15, 438. [CrossRef]

46. Pebesma, E.; Graler, B. Introduction to Spatio-Temporal Variography; University of Münster: Münster, Germany, 2021.

47. Song, Y.-Z.; Yang, H.-L.; Peng, J.-H.; Song, Y.-R.; Sun, Q.; Li, Y. Estimating PM 2.5 concentrations in Xi'an City using a generalized additive model with multi-source monitoring data. PLoS ONE 2015, 10, e0142149. [CrossRef] [PubMed]

48. Song, W.; Jia, H.; Huang, J.; Zhang, Y. A satellite-based geographically weighted regression model for regional PM 2.5 estimation over the Pearl River Delta region in China. Remote. Sens. Environ. 2014, 154, 1-7. [CrossRef]

49. Van Donkelaar, A.; Martin, R.V.; Spurr, R.J.D.; Burnett, R.T. High-resolution satellite-derived PM 2.5 from optimal estimation and geographically weighted regression over North America. Environ. Sci. Technol. 2015, 49, 10482-10491. [CrossRef]

50. Mirzaei, M.; Bertazzon, S.; Couloigner, I.; Farjad, B.; Ngom, R. Estimation of local daily PM 2.5 concentration during wildfire episodes: Integrating MODIS AOD with multivariate linear mixed effect (LME) models. Air Qual. Atmos. Health 2019, 13, 173-185. [CrossRef]

51. Xie, Y.; Wang, Y.; Zhang, K.; Dong, W.; Lv, B.; Bai, Y. Daily estimation of ground-Level PM $_{2.5}$ concentrations over Beijing using $3 \mathrm{~km}$ resolution MODIS AOD. Environ. Sci. Technol. 2015, 49, 12280-12288. [CrossRef] [PubMed]

52. Ma, J.; Yu, Z.; Qu, Y.; Xu, J.; Cao, Y. Application of the XGBoost machine learning method in PM 2.5 prediction: A case study of Shanghai. Aerosol Air Qual. Res. 2020, 20, 128-138. [CrossRef]

53. Pan, B. Application of XGBoost algorithm in hourly $\mathrm{PM}_{2.5}$ concentration prediction. IOP Conf. Ser. Earth Environ. Sci. 2018, 113, 012127. [CrossRef]

54. Hu, X.; Belle, J.H.; Meng, X.; Wildani, A.; Waller, L.A.; Strickland, M.J.; Liu, Y. Estimating PM $_{2.5}$ concentrations in the conterminous United States using the random forest approach. Environ. Sci. Technol. 2017, 51, 6936-6944. [CrossRef]

55. Li, L.; Fang, Y.; Wu, J.; Wang, J.; Ge, Y. Encoder-decoder full residual deep networks for robust regression and spatiotemporal estimation. IEEE Trans. Neural Networks Learn. Syst. 2021, 32, 4217-4230. [CrossRef] [PubMed]

56. Spielman, D. Spectral Graph Theory. In Combinatorial Scientific Computing; Routledge: London, UK, $2012 ;$ pp. 495-524. 
57. Jain, A.; Liu, I.; Sarda, A.; Monino, P. Food Discovery with Uber Eats: Using Graph Learning to Power Recommendations. Available online: https:/ / eng.uber.com/uber-eats-graph-learning/ (accessed on 1 March 2021).

58. Ying, R.; He, R.; Chen, K.; Eksombatchai, P.; Hamilton, W.L.; Leskovec, J. Graph Convolutional Neural Networks for Web-Scale Recommender Systems. In Proceedings of the 24th ACM SIGKDD International Conference on Knowledge Discovery \& Data Mining, London, UK, 19-23 August 2018; pp. 974-983.

59. Watters, N.; Tacchetti, A.; Weber, B.; Pascanu, R.; Zoran, D. Visual Interaction Networks: Learning a Physics Simulator from Video. In Proceedings of the 31st Conference on Neural Information Processing Systems (NIPS 2017), Long Beach, CA, USA, 4-9 December 2017.

60. Mirhoseini, A.; Goldie, A.; Yazgan, M.; Jiang, J. Chip placement with deep reinforcement learning. arXiv 2020, arXiv:2004.10746.

61. Sarlin, P.-E.; DeTone, D.; Malisiewicz, T.; Rabinovich, A. SuperGlue: Learning Feature Matching with Graph Neural Networks. In Proceedings of the 2020 IEEE/CVF Conference on Computer Vision and Pattern Recognition (CVPR), Seattle, WA, USA, 13-19 June 2020.

62. Chanussot, L.; Das, A.; Goyal, S.; Lavril, T.; Shuaibi, M.; Riviere, M.; Tran, K.; Heras-Domingo, J.; Ho, C.; Hu, W.; et al. Open catalyst 2020 (OC20) dataset and community challenges. ACS Catal. 2021, 11, 6059-6072. [CrossRef]

63. Stokes, J.M.; Yang, K.; Swanson, K.; Jin, W.; Cubillos-Ruiz, A.; Donghia, N.M.; Macnair, C.R.; French, S.; Carfrae, L.A.; BloomAckermann, Z.; et al. A deep learning approach to antibiotic discovery. Cell 2020, 180, 688-702. [CrossRef] [PubMed]

64. Gaudelet, T.; Day, B.; Jamasb, A.; Soman, J.; Regep, C.; Liu, G.; Hayter, J.; Vickers, R.; Roberts, C.; Tang, J.; et al. Utilizing graph machine learning within drug discovery and development. arXiv 2021, arXiv:2012.05716.

65. Hamilton, W.L.; Ying, R.; Leskovec, J. Inductive Representation Learning on Large Graphs. In Proceedings of the 31st International Conference on Neural Information Processing Systems 2017 (Nips 2017), Long Beach, CA, USA, 4-9 December 2017; pp. 1025-1035.

66. Ge, L.; Wu, K.; Zeng, Y.; Chang, F.; Wang, Y.; Li, S. Multi-scale spatiotemporal graph convolution network for air quality prediction. Appl. Intell. 2021, 51, 3491-3505. [CrossRef]

67. Qi, Y.; Li, Q.; Karimian, H.; Liu, D. A hybrid model for spatiotemporal forecasting of $\mathrm{PM}_{2.5}$ based on graph convolutional neural network and long short-term memory. Sci. Total Environ. 2019, 664, 1-10. [CrossRef]

68. Abadal, S.; Jain, A.; Guirado, R.; López-Alonso, J.; Alarcón, E. Computing graph neural networks: A survey from algorithms to accelerators. ACM Comput. Surv. 2021, 54,1-38. [CrossRef]

69. China Meteorological Administration. China Climate Bulletin 2020; China Meteorological Administration: Beijing, China, 2020. (In Chinese)

70. Tang, W.-J.; Yang, K.; Qin, J.; Cheng, C.C.K.; He, J. Solar radiation trend across China in recent decades: A revisit with qualitycontrolled data. Atmos. Chem. Phys. Discuss. 2011, 11, 393-406. [CrossRef]

71. Wikipedia. China Climate. Available online: https://zh.wikipedia.org/zh-cn/\%E4\%B8\%AD \%E5\%9B\%BD $\%$ E6\%B0\%94\%E5\%8 0\%99 (accessed on 10 July 2021). (In Chinese).

72. Ding, Y. China Climate; Science Press: Beijing, China, 2013. (In Chinese)

73. Gelaro, R.; McCarty, W.; Suárez, M.J.; Todling, R.; Molod, A.; Takacs, L.; Randles, C.A.; Darmenov, A.; Bosilovich, M.G.; Reichle, R.; et al. The Modern-Era Retrospective Analysis for Research and Applications, Version 2 (MERRA-2). J. Clim. 2017, 30, 5419-5454. [CrossRef] [PubMed]

74. Yang, S.; Chen, B. Driving forces of particulate matter emissions in China. Energy Procedia 2017, 105, 4601-4606. [CrossRef]

75. Yan, B.; Liu, S.; Zhao, B.; Li, X.; Fu, Q.; Jiang, G. China's fight for clean air and human health. Environ. Sci. Technol. 2018, 52, 8063-8064. [CrossRef] [PubMed]

76. Cheng, Z.; Luo, L.; Wang, S.; Wang, Y.; Sharma, S.; Shimadera, H.; Wang, X.; Bressi, M.; de Miranda, R.M.; Jiang, J.; et al. Status and characteristics of ambient $\mathrm{PM}_{2.5}$ pollution in global megacities. Environ. Int. 2016, 89-90, 212-221. [CrossRef] [PubMed]

77. Wang, W.; Zhao, S.; Jiao, L.; Taylor, M.; Zhang, B.; Xu, G.; Hou, H. Estimation of $\mathrm{PM}_{2.5}$ concentrations in China using a spatial back propagation neural network. Sci. Rep. 2019, 9, 1-10. [CrossRef] [PubMed]

78. Nosratabadi, A.R.; Graff, P.; Karlsson, H.; Ljungman, A.G.; Leanderson, P. Use of TEOM monitors for continuous long-term sampling of ambient particles for analysis of constituents and biological effects. Air Qual. Atmos. Health 2019, 12, 161-171. [CrossRef]

79. Guo, J.-P.; Zhang, X.-Y.; Che, H.; Gong, S.-L.; An, X.; Cao, C.-X.; Guang, J.; Zhang, H.; Wang, Y.-Q.; Xue, M.; et al. Correlation between PM concentrations and aerosol optical depth in eastern China. Atmos. Environ. 2009, 43, 5876-5886. [CrossRef]

80. Li, L. High-resolution mapping of aerosol optical depth and ground aerosol coefficients for mainland China. Remote. Sens. 2021, 13, 2324. [CrossRef]

81. Li, L.; Franklin, M.; Girguis, M.; Lurmann, F.; Wu, J.; Pavlovic, N.; Breton, C.; Gilliland, F.; Habre, R. Spatiotemporal imputation of MAIAC AOD using deep learning with downscaling. Remote. Sens. Environ. 2020, 237, 111584. [CrossRef] [PubMed]

82. Seger, C. An Investigation of Categorical Variable Encoding Techniques in Machine Learning: Binary Versus One-Hot and Feature Hashing; KTH Royal Institute of Technology: Stockholm, Sweden, 2018.

83. NASA. MERRA-2 GMI. Available online: https://acd-ext.gsfc.nasa.gov/Projects/GEOSCCM/MERRA2GMI/ (accessed on 1 June 2020).

84. Press, H.W.; Teukolsky, A.S.; Vetterling, T.W.; Flannery, P.B. Numerical Recipes in C: The Art of Scientific Computing, 2nd ed.; Cambridge University Press: New York, NY, USA, 1992; pp. 123-128. 
85. Fang, Y.; Li, L. Estimation of high-precision high-resolution meteorological factors based on machine learning. J. Geo-Inform. Sci. 2019, 21, 799-813.

86. Li, L. Geographically weighted machine learning and downscaling for high-resolution spatiotemporal estimations of wind speed. Remote. Sens. 2019, 11, 1378. [CrossRef]

87. Iglewicz, B.; Hoaglin, C.D. How to detect and handle outliers. In The ASQ Basic References in Quality Control: Statistical Techniques; Mykytka, F.E., Ed.; American Society for Quality: Milwaukee, WI, USA, 1993.

88. Wang, X.; Dickinson, R.E.; Su, L.; Zhou, C.; Wang, K. PM 2.5 pollution in China and how it has been exacerbated by terrain and meteorological conditions. Bull. Am. Meteorol. Soc. 2018, 99, 105-119. [CrossRef]

89. Zhai, S.; Jacob, D.J.; Wang, X.; Shen, L.; Li, K.; Zhang, Y.; Gui, K.; Zhao, T.; Liao, H. Fine particulate matter (PM $\left.\mathrm{PM}_{2.5}\right)$ trends in China, 2013-2018: Separating contributions from anthropogenic emissions and meteorology. Atmos. Chem. Phys. Discuss. 2019, 19, 11031-11041. [CrossRef]

90. Dyatmika, H.; Sambodo, K.; Budiono, M.; Hendayani, B. Noise removal using thresholding and segmentation for random noise Sentinel-1 data. IOP Conf. Ser. Earth Environ. Sci. 2017, 54, 012105. [CrossRef]

91. Freedman, D.; Pisani, R.; Purves, R. Statistics: Fourth International Student Edition; W.W. Norton \& Company: New York, NY, USA, 2007.

92. Zhou, J.; Cui, G.; Hu, S.; Zhang, Z.; Yang, C.; Liu, Z.; Wang, L.; Li, C.; Sun, M. Graph neural networks: A review of methods and applications. AI Open 2020, 1, 57-81. [CrossRef]

93. Tobler, W. On the First Law of Geography: A Reply. Ann. Assoc. Am. Geogr. 2004, 94, 304-310. [CrossRef]

94. Kipf, T.; Welling, M. Semi-supervised classification with graph convolutional networks. arXiv 2016, arXiv:1609.02907.

95. Chen, D.; Lin, Y.; Li, W.; Li, P.; Zhou, J.; Sun, X. Measuring and Relieving the Over-Smoothing Problem for Graph Neural Networks from the Topological View. In Proceedings of the AAAI Conference on Artificial Intelligence 2020, New York, NY, USA 7-12 February 2020; Volume 34, pp. 3438-3445.

96. Li, L.; Girguis, M.; Lurmann, F.; Pavlovic, N.; McClure, C.; Franklin, M.; Wu, J.; Oman, L.D.; Breton, C.; Gilliland, F.; et al. Ensemble-based deep learning for estimating $\mathrm{PM}_{2.5}$ over California with multisource big data including wildfire smoke. Environ. Int. 2020, 145, 106143. [CrossRef] [PubMed]

97. Gong, P.; Li, X.; Zhang, W. 40-Year (1978-2017) human settlement changes in China reflected by impervious surfaces from satellite remote sensing. Sci. Bull. 2019, 64, 756-763. [CrossRef]

98. Bishop, M.C. Pattern Recognition and Machine Learning; Springer: Berlin/Heidelberg, Germany, 2006.

99. Lundberg, S.M. Welcome to the SHAP Documentation. Available online: https://shap.readthedocs.io/en/latest/index.html (accessed on 5 January 2021).

100. Lundberg, S.M.; Lee, S.I. A Unified Approach to Interpreting Model Predictions. In Proceedings of the 31st International Conference on Neural Information Processing Systems (Nips 2017), Long Beach, CA, USA, 4-9 December 2017; pp. $4768-4777$.

101. Baidu. 4.15 Sandstorm in Beijing. Available online: https:/ / baike.baidu.com $/$ item $/ 4 \% C 2 \% B 715 \% E 5 \% 8 C \% 97 \% E 4 \% B A \% A C \% E 6$ \%B2\%99\%E5\%B0\%98\%E6\%9A\%B4 (accessed on 12 April 2021).

102. Li, X.; Jin, L.; Kan, H. Air pollution: A global problem needs local fixes. Nature 2019, 570, 437-439. [CrossRef]

103. Baidu. Beijing Clean Air Action Plan for 2013-2017. Available online: https://baike.baidu.com/item/\%E5\%8C\%97\%E4\%BA \% AC\%E5\%B8\%822013-2017\%E5\%B9\%B4\%E6\%B8\%85\%E6\%B4\%81\%E7\%A9\%BA\%E6\%B0\%94\%E8\%A1\%8C\%E5\%8A\%A8\%E8 $\% A E \% A 1 \% E 5 \% 88 \% 92 / 10348277$ ?fr=aladdin (accessed on 2 January 2021). (In Chinese).

104. Pang, N.; Gao, J.; Zhu, G.; Hui, L.; Zhao, P.; Xu, Z.; Tang, W.; Chai, F. Impact of clean air action on the PM 2.5 pollution in Beijing, China: Insights gained from two heating seasons measurements. Chemosphere 2021, 263, 127991. [CrossRef] [PubMed]

105. Saunders, A.; Oldenburg, I.A.; Berezovskii, V.; Johnson, C.A.; Kingery, N.D.; Elliott, H.L.; Xie, T.; Gerfen, C.R.; Sabatini, B.L. A direct GABAergic output from the basal ganglia to frontal cortex. Nat. Cell Biol. 2015, 521, 85-89. [CrossRef] [PubMed]

106. Montero, J.; Fernandez-Aviles, G.; Mateu, J. Spatial and Spatio-Temporl Geostatistical Modeling and Kriging; Wiler \& Sons: Hoboken, NJ, USA, 2015.

107. Goodfellow, I.; Bengio, Y.; Courville, A. Deep Learning; MIT Press: Cambridge, MA, USA, 2016.

108. Zhang, Z.; Luo, P.; Loy, C.C.; Tang, X. Learning deep representation for face alignment with auxiliary attributes. IEEE Trans. Pattern Anal. Mach. Intell. 2016, 38, 918-930. [CrossRef] [PubMed]

109. Fan, H.; Zhao, C.; Yang, Y.; Yang, X. Spatiotemporal variations of the $\mathrm{PM}_{2.5} / \mathrm{PM}_{10}$ ratios and its application to air pollution type classification in China. Front. Environ. Sci. 2021, 9, 218. [CrossRef]

110. Abatzoglou, T.J. Development of gridded surface meteorological data for ecological applications and modelling. Int. J. Climatol. 2011, 33, 121-131. [CrossRef] 